\title{
REVIEW
}

\section{Regulation of the androgen receptor by post-translational modifications}

\author{
Kelly Coffey and Craig N Robson \\ Solid Tumour Target Discovery Group, The Medical School, Newcastle Cancer Centre at the Northern Institute for Cancer Research, Newcastle University, \\ Paul O'Gorman Building, Framlington Place, Newcastle upon Tyne, Tyne and Wear NE2 4HH, UK \\ (Correspondence should be addressed to C N Robson; Email: c.n.robson@ncl.ac.uk)
}

\begin{abstract}
The androgen receptor (AR) is a key molecule in prostate cancer and Kennedy's disease. Understanding the regulatory mechanisms of this steroid receptor is important in the development of potential therapies for these diseases. One layer of AR regulation is provided by post-translational modifications including phosphorylation, acetylation, sumoylation, ubiquitination and methylation. While these
\end{abstract}

modifications have mostly been studied as individual events, it is becoming clear that these modifications can functionally interact with each other in a signalling pathway. In this review, the effects of all modifications are described with a focus on interplay between them and the functional consequences for the AR.

Journal of Endocrinology (2012) 215, 221-237

\section{Introduction}

The androgen receptor (AR; Fig. 1) is a steroid hormone receptor that plays a critical role in prostate cancer (PC) progression and development. In addition, it can also cause spinal bulbar muscular dystrophy (commonly referred to as Kennedy's disease). Hence, this $110 \mathrm{kDa}$ protein is the target of many therapeutic strategies. The AR, in the absence of ligand, is sequestered to the cytoplasm by heat-shock proteins, which mask a nuclear localisation sequence (NLS). Upon binding to its androgen ligand, these chaperone proteins dissociate and the AR dimerises, resulting in a conformational change, which exposes the NLS. This results in the AR translocating to the nucleus where it can bind to androgen response elements (AREs) and activate androgen-responsive genes. The regulation of this transcription factor in this process is achieved via a multitude of mechanisms involving interaction with other co-activator and repressor proteins, some of which are responsible for modification of the receptor at the post-translational level to modulate its activity. Specifically, modulation of AR activity by post-translational modifications (PTMs) can be achieved through regulation of protein stability, interaction with other proteins, cellular localisation and structure of the receptor itself. Therefore, discovery and study of these modifications and the enzymes that perform the addition are critical to discover novel therapeutic options.
Many of the enzymes that are responsible for the modification of the receptor are dysregulated in disease, which results in aberrant AR activity. More recently, the interplay between protein PTMs is becoming apparent. Where these modifications were thought to result in a simple signal for the molecule to alter its activity or interaction with other proteins, it is now clear that combinations of modifications act together to provide a more complex message to the cell; a sentence of instructions rather than one simple word.

Numerous PTM sites have been described on the AR. The types of modifications include phosphorylation, acetylation, ubiquitination, sumoylation and more recently methylation (Me).

\section{Acetylation of the AR}

AR acetylation (AR-Ac) was first inferred by studies using the histone deacetylase (HDAC) inhibitor trichostatin A (TSA), which showed that in the presence of dihydrotestosterone (DHT), transcription, chromatin remodelling and AR levels were enhanced (List et al. 1999). Direct AR-Ac was first described in 2000 (Fu et al. 2000) after other transcription factors, including p53 (Gu \& Roeder 1997) and Kruppel-like factor (Song et al. 2003), were found to be acetylated. Edman degradation demonstrated that all three lysine residues (K630, K632 and K633) within the KLKK motif can be targeted by 


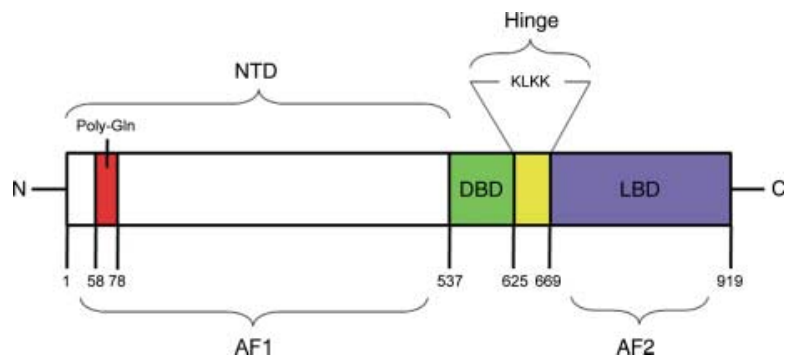

Figure 1 The structure of the androgen receptor $(A R)$. The $A R$ is composed of a number of domains: the $\mathrm{N}$-terminal domain (NTD) that contains the poly-GIn (CAG) repeat sequence important in Kennedy's disease and the activation function 1 (AF1) domain, the DNA binding domain (DBD), the ligand binding domain (LBD) containing the activation function 2 (AF2) domain and the hinge region where the KLKK motif resides.

the acetylases p300 and p300/CREB binding protein (CBP)associated factor (PCAF; Fu et al. 2000) similar to the KSKK motif in p53 (Gu \& Roeder 1997). In later studies, Tip60 (Gaughan et al. 2002) and $N$-acetyltransferase arrest-defect 1 protein (Wang et al. 2012) were also found to directly acetylate the AR.

The role of AR-Ac has been investigated in many studies where acetyl acceptor sites have been mutated to be either non-functional or acetylation mimetic, the findings of which are summarised in Table 1. Generally, when the AR cannot be acetylated, TSA can no longer activate the AR, and co-activation by SRC1, p300, PCAF, Ubc9 and Tip60 is abolished resulting in reduced recruitment to AREs. Under these conditions, the AR equilibrium moves towards a repressed form, which has increased binding to co-repressor proteins including NCoR, and subsequent MEKK1 stimulation can no longer induce AR-mediated apoptosis (Fu et al. 2000, 2003, Xu et al. 2009). Sumoylation and transrepression functions of the AR remain unaffected by mutation of acetyl acceptor sites (Fu et al. 2000, 2003, Xu et al. 2009), suggesting that there is no functional interaction between sumoylation and acetylation. When all acetylation acceptor sites are mutated to glutamine to mimic acetylation, the opposite is observed, with enhanced AR-p300 interaction and reduced interaction with co-repressor proteins such as NCoR, HDACs, and SMAD3 (Fu et al. 2003). Under androgendepleted conditions, AR-Ac mimics exhibit nuclear localisation, while mutants that cannot be acetylated remain in the cytoplasm even with androgen stimulation (Shiota et al. 2010). SMAD3/SMAD4 can interact with the AR DNA binding domain (DBD) and ligand binding domain (LBD) to repress AR-Ac and inhibit AR activity (Kang et al. 2002). Hence, AR-Ac has been robustly demonstrated to facilitate activation of the AR.

Acetylation is a dynamic process that is reversed by HDAC enzymes. 5'-TG-3' interacting factor recruits HDAC1, mediated by Sin3a (Sharma \& Sun 2001), to deacetylate the $\mathrm{AR}$ and down-regulate AR activity (Gaughan et al. 2002).
Interestingly, HDAC7 has also been found to inhibit AR; however, the mechanism for this is independent of AR acetyl acceptor sites (Karvonen et al. 2006). Modulation of AR-Ac is also critical for control of AR activity during the cell cycle. AR-Ac mimics, for example, yield enhanced cell survival, proliferation and AR-regulated gene expression as a consequence of increased levels of the cell cycle control genes, cyclin D and cyclin E (Fu et al. 2003). Cyclin D1 can also disrupt the interaction between PCAF and AR, thereby altering the AR-Ac profile and potentially inhibiting AR transcriptional activity at the G1/S transition (Martinez \& Danielsen 2002).

AR-Ac can also regulate DNA binding and activation of transcription in a promoter-dependent context. For example, upon mutation of all acetyl acceptors, the mouse Muc1 (Pem) promoter is not activated while prostate-specific antigen $(P S A ; K L K 3)$ remains active and the $M M T V$ promoter is activated to a higher level than with WT AR. This differential transcriptional ability of acetylation site mutants of AR suggests the receptor can recruit different coregulator proteins depending on which sites can be acetylated (Faus \& Haendler 2008). One study specifically addressed the role of the hinge region, which contains the KLKK motif, in the regulation of AR activity by generating an AR mutant that lacked residues 629-636. As detailed in Table 1, this mutant AR displayed a stronger androgen response but it had low affinity for ARE binding sites, which is not surprising as these effects were independent of nuclear localisation. This deletion construct also displayed an enhanced $\mathrm{N}$ and $\mathrm{C}$ terminal interaction and could be inhibited by anti-androgen treatment (Haelens et al. 2007). These findings are contradictory to the published work on AR-Ac mutants, which highlights the role of the intact hinge region in the regulation of AR activity and how PTM can influence its function.

Acetylation of the AR is induced by androgen stimulation (Fu et al. 2000); however, there are other cellular stimuli that can influence the levels of AR-Ac. The neuropeptide, bombesin, which has been demonstrated to play a role in PC progression, has a positive impact on p300 activity. This can be further stimulated by Src to enhance AR-Ac levels (Gong et al. 2006). Similarly, IL4 has been found to activate the AR in the absence of androgens via elevation of $\mathrm{CBP} / \mathrm{p} 300$ levels to enhance $\mathrm{AR}-\mathrm{Ac}$ and stimulate castrate-resistant PC (CRPC; Lee et al. 2009). The activity of the AR can also be altered through acetylation of other proteins that can modulate the AR. For example, P300 acetylates $\beta$-catenin, regulating its interaction with TCF and the AR to result in enhanced receptor transcriptional activity to regulate a subset of genes in a ligand-dependent manner (Levy et al. 2004). Another example is HSP90-Ac, which results in destabilisation of the AR leading to its destruction by the proteasome (Ai et al. 2009, Gibbs et al. 2009).

Due to the oncogenic effects of an acetylated AR, many laboratories, including our own, have investigated the potential of histone acetyltransferase (HAT) inhibition as 
Table 1 Androgen receptor acetylation and methylation mutants

\section{Mutant}

$\mathrm{AR}^{(\mathrm{K} 630 \mathrm{~A})}$

$\mathrm{AR}^{(\mathrm{K} 630 \mathrm{R})}$

$\mathrm{AR}^{(\mathrm{K} 630 \mathrm{Q})}$

$\mathrm{AR}^{(\mathrm{K} 630 \mathrm{~T})}$

$\mathrm{AR}^{(\mathrm{K} 632 \mathrm{R})}$

$\mathrm{AR}^{(\mathrm{K} 632 \mathrm{~A} / \mathrm{K} 633 \mathrm{~A})}$

$\mathrm{AR}^{(\mathrm{K} 630 / 632 / 633 \mathrm{~A})}$

$\mathrm{AR}^{(\mathrm{K} 630 \mathrm{R} / 632 \mathrm{R} / 633 \mathrm{R})}$

$\mathrm{AR}^{(\mathrm{K} 630 \mathrm{Q} / 632 \mathrm{Q} / 633 \mathrm{Q})}$

$\mathrm{AR}^{(629-636 \text { deletion })}$

\section{AR characteristics}

Decreased activation by DHT

No effect on sumoylation

Abolished co-activation by SRC1, p300, Ubc9, Tip60

No TSA-mediated activation

Increased binding to $\mathrm{NCoR}$

Transrepression unaffected

Impaired activation by PKA inhibition

Decreased ligand-induced phosphorylation

Decreased N/C interaction

Decreased p300 binding

Enhanced co-repressor binding

Acetylation mimic

Enhanced p300 binding

Reduced binding of NCoR, HDAC and SMAD3

Transrepression unaffected

Acetylation mimic

Enhanced p300 binding

Reduced binding of NCoR, HDAC and SMAD3

Transrepression unaffected

Resistant to SIRT1-mediated repression

Decreased PCAF interaction

Abolished co-activation by Set 9

No methylation

Decreased activation by DHT

Misfolding and aggregation

No effect on sumoylation

Abolished co-activation by SRC1, p300, PCAF, Ubc9, Tip60

No TSA-mediated activation

Increased binding to NCoR

Transrepression unaffected

Impaired activation by PKA inhibition

Decreased ligand-induced phosphorylation

Impaired nuclear translocation

No alteration in DNA binding

Remains cytoplasmic despite ligand stimulation

Acetylation mimic

Translocates to the nucleus even during starvation

Enhanced androgen response

Reduced DNA binding

Can be inhibited by anti-androgens

Unaffected nuclear localisation

Enhanced N/C interaction

\section{Phenotypic effects}

Resistant to apoptotic stimuli

genes

Decreased apoptosis

Increased cell cycle regulatory genes

Decreased apoptosis

Has been found as a somatic mutation

u et al. (2003)

Gaughan et al. (2011)

Fu et al. (2003)

Fu et al. (2003)

Fu et al. (2006)

Shi et al. (2002)

Gaughan et al. (2011)

Delayed ligand-dependent

nuclear translocation

Resistant to apoptotic stimuli

Fu et al. (2000)

Thomas et al. (2004)

Fu et al. (2002)

Fu et al. (2004)

Effect on gene activation promoter dependent
Faus \& Haendler (2008)

Shiota et al. (2010)

Shiota et al. (2010)

Haelens et al. (2007) a therapy for PC. AR-Ac has been shown to be inhibited by Rosa rugosa Thunb. (Rosaceae) extracts (Lee et al. 2008), Resveratrol (a polyphenolic phytoalexin; Harada et al. 2011), procyanidin B3 (Choi et al. 2011), green tea catechins (Lee et al. 2012) and allspice (Lee et al. 2007), all of which result in a decrease in cancer cell proliferation but not all by the same mechanism, as detailed in Table 2 . Furthermore, many HAT inhibitors have been described recently, which are targeted against specific enzymes such as p300 (curcumin) and Tip60 (NU9056, K Coffey \& C N Robson 2012, unpublished data).

\section{Me of the AR}

Regulation of AR activity can be achieved indirectly via $\mathrm{Me}$ of histone proteins. Me and demethylation of histone proteins are emerging as a key process in the initiation and regulation of transcription. Furthermore, many lysine demethylases (KDMs) and methyltransferases (KMTs) have been detailed as nuclear receptor coregulator proteins with direct AR-Me being documented in 2011 by Gaughan et al. (2011), which was quickly followed by a second report by Ko et al. (2011). Both studies described Set9-mediated AR-Me as 
Table 2 Acetylation inhibitors and their effects on AR

\section{Compound name}

Allspice

Rosaceae

Procyanidin B3 (Pro-B3)

Resveratrol

Green tea catechins

\section{AR-specific effects of reduced AR acetylation}

Inhibits p300 and CBP activity

Suppressed ligand-mediated activation

Enhanced effects of AR antagonist

Inhibition of p300-mediated AR-Ac

Inhibits AR-mediated transcription

$$
\begin{aligned}
& \text { No effect on nuclear translocation at early } \\
& \text { timepoints } \\
& \text { Reduced nuclear AR at later timepoints } \\
& \text { Reduced DNA binding } \\
& \text { Reduced AR protein levels } \\
& \text { Inhibited nuclear translocation in response to } \\
& \text { ligand } \\
& \text { Suppressed ligand-mediated activation } \\
& \text { Reduced AR-dependent gene transcription }
\end{aligned}
$$

\section{Functional effects of reduced AR acetylation}

Inhibits PC cell growth

Inhibits PC cell growth

Inhibition of proliferation

Inhibition of cell cycle gene expression

Increased cell death

\section{Reference}

Lee et al. (2007)

Lee et al. (2008)

Choi et al. (2011)

Harada et al. (2011)

PC cell death

Lee et al. (2012) a transcriptional activator. In both reports, Set9 was shown to interact with $\mathrm{AR}$ and facilitate the interaction between the $\mathrm{N}$ and $\mathrm{C}$ terminal domains. Set9 was further demonstrated to interact with AREs in response to androgen stimulation. However, there are some discrepancies between the two reports, which need to be addressed. First, the identified sites of Me upon the AR protein are different. Gaughan et al. used a combination of mass spectrometry, immunoprecipitation and studies with short mutant AR peptides to demonstrate AR-Me within the KLKK motif of the hinge region at Lys632. Alternatively, Ko et al. used immunoprecipitation and mutant AR protein fragments to demonstrate that AR-Me occurs in the same region but at Lys630. While both studies robustly demonstrate their findings, differences in experimentation between the use of short peptides or larger fragments of AR may explain the discrepancy in Me site identification. Alternatively, multiple Me states may exist under different circumstances.

To date, these are the only two studies that describe direct Me of the AR, while demethylation of the AR has not yet been reported. Hence, Set9 may not be the only KMT that can methylate the AR. Indeed, many KMTs and KDMs have been described as AR co-regulator proteins without $A R$ $\mathrm{Me} /$ demethylation being investigated.

\section{Phosphorylation of the AR}

Phosphorylation of the AR has been studied for nearly 40 years and is therefore the most characterised of all PTMs. As this topic has been extensively reviewed in the past (Faus \& Haendler 2006, Ward \& Weigel 2009, Gioeli \& Paschal 2012) and information is comprehensively detailed within phosphosite (www.phosphosite.org), a less detailed description will be presented here that highlights the importance of AR phosphorylation (AR-P) in the regulation of its function and how it can interact with other PTMs. The complexity of
AR-P as a component of a signalling pathway is quite staggering and perhaps demonstrates how pathways will evolve for other types of PTMs over the next 40 years.

First reported in 1984 (Goueli et al. 1984), AR-P was initially thought to facilitate ligand binding (Golsteyn et al. 1989). The first direct evidence of AR-P was reported in 1990, when it was found that stimulation of the LNCaP PC cell line with the androgen DHT resulted in stimulation of AR-P (van Laar et al. 1990). As AR-P was only found in nuclear fractions, it was suggested that AR-P takes place after transformation to the active state (Golsteyn et al. 1990). In fact, the AR is phosphorylated within 15 min of synthesis to allow ligand binding (Blok et al. 1998) but undergoes further phosphorylation events upon androgen stimulation (Kuiper et al. 1991, van Laar et al. 1991, Kuiper \& Brinkmann 1995). Much debate then followed as to whether the AR was phosphorylated in response to androgens or whether this effect was due to total AR levels increasing in response to androgen treatment (Kemppainen et al. 1992, Kuiper et al. 1993). The AR was later demonstrated to be phosphorylated under conditions of androgen depletion (Beitel et al. 1995). Indeed, AR-P can determine whether or not AR ligands perform as agonists or antagonists, and mutations in these sites can convert antagonists into agonists (Wang et al. 1999b).

\section{Serine phosphorylation}

There are multiple serine residues within the AR that can be phosphorylated (Table 3). Some are better characterised than others, although overall the function and validity of some of the sites is still unclear due to conflicting findings. For example, Ser81 was described as phosphorylated by protein kinase C (PKC); however, this was not supported by inhibitor studies (Gioeli et al. 2002). Caution should also be taken when investigating AR-P in the literature as some of the phosphorylation sites are given different numbers, which can confuse the reader. For example, Ser210 is described as 


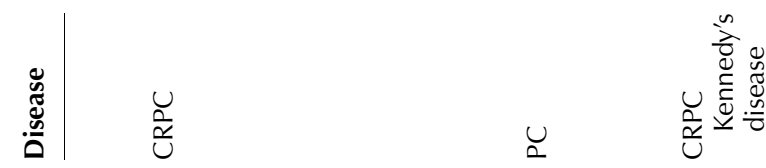

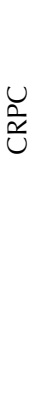

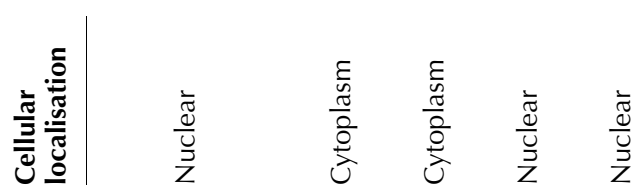
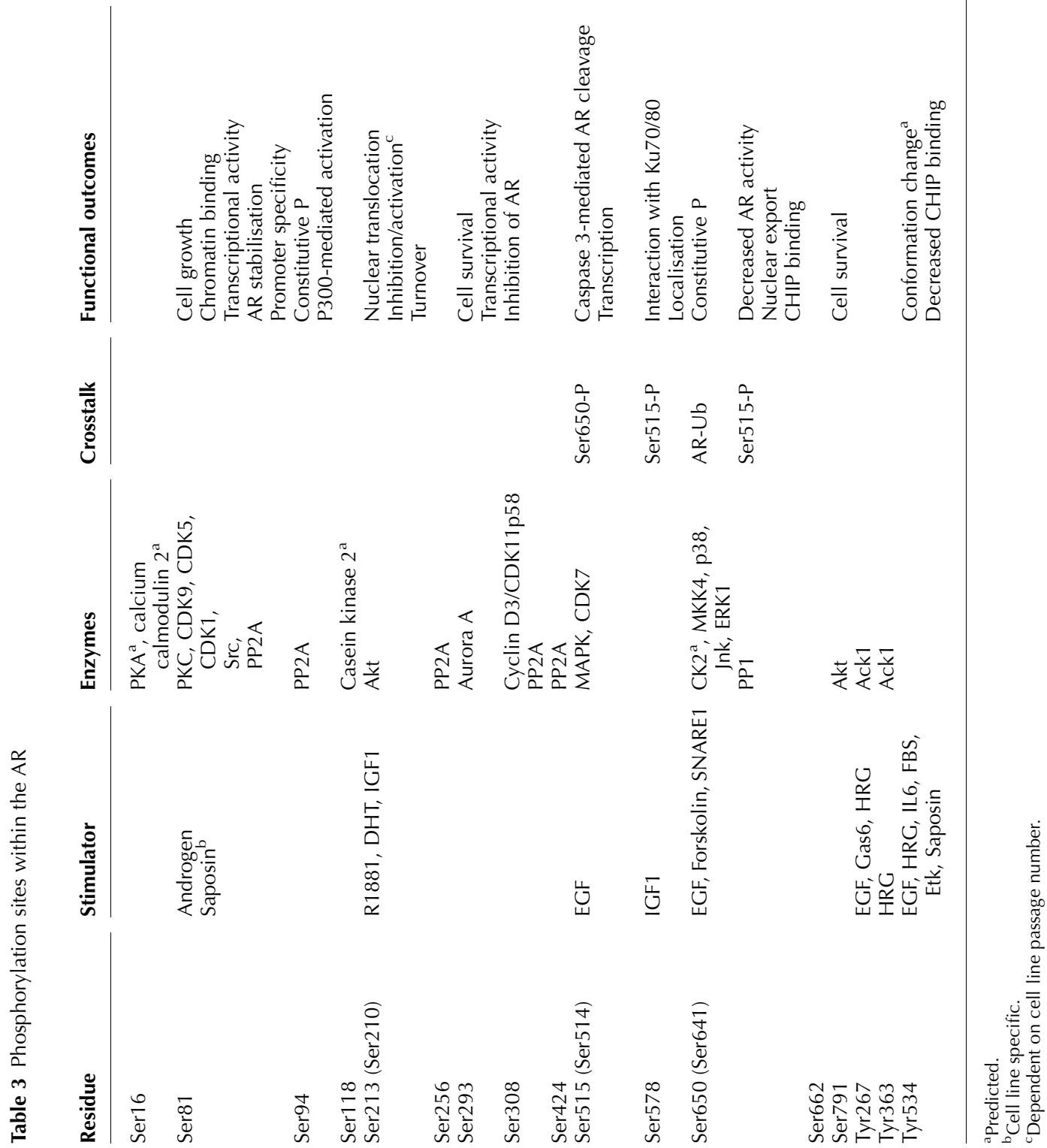
phosphorylated (Lin et al. 2001b, 2003, McCall et al. 2008, Shank et al. 2008, Bryant et al. 2011); however, when referring to the standard AR protein sequence (ANDR HUMAN, P10275), an arginine is found at this site, while in other studies, the same serine in question is referred to as Ser213 (Wen et al. 2000, Nan et al. 2003, Burgdorf et al. 2004, Taneja et al. 2005, Kim \& Lee 2009, Lee 2009). In this review, the nomenclature used will correspond to the standard sequence to avoid such confusion.

Constitutive phosphorylation of the AR is seen at Ser94 (Jenster et al. 1994) and Ser650 (Wong et al. 2004). Similar to Ser81, p-Ser94 is required to generate the $112 \mathrm{kDa}$ form of the AR (Jenster et al. 1994). However, in contrast to Ser81, which is a nuclear event, p-Ser94 occurs in the cytoplasm (Kesler et al. 2007). Interestingly, mutation of Ser94 and Ser81 has little effect on transcription (Zhou et al. 1995). In response to androgens, p-Ser81 is the most abundant (Lee et al. 2007); however, it can occur at low levels of androgen, for example, in LNCaP cells Ser81 is phosphorylated in response to as little as $1 \mathrm{nM} \mathrm{DHT,} \mathrm{while} \mathrm{in} \mathrm{C4-2} \mathrm{cells} \mathrm{concentrations} \mathrm{of} \mathrm{between}$ 10 and 100 pM is sufficient (Chen et al. 2006). Ser308 was found to be phosphorylated in the presence of androgens using MALDI/TOF-MS (Zhu et al. 2001), with mutation of this site to alanine inconsistently increasing transcriptional activity (Gioeli et al. 2002), yet cyclin D3/CDK11p58 can phosphorylate this site both in vitro and in vivo to result in inhibition of AR activity (Zong et al. 2007), suggesting that this residue may be phosphorylated as a mechanism for receptor down-regulation in the nucleus.

\section{Protein kinases involved in $A R-P$}

Initially, protein kinase A (PKA) and PKC were investigated as $\mathrm{AR}$ kinases as their activation resulted in enhanced $\mathrm{AR}$ activity in the presence of ligand (Ikonen et al. 1994). PKAmediated AR activation is not a result of increased AR levels or increased DNA binding capacity; furthermore, AR does not contain PKA recognition sites, which led the investigators to conclude that the effects of PKA on $\mathrm{AR}$ are indirect (Ikonen et al. 1994). Similarly, while PKC activation stimulates AR activity, no additional phosphorylation was observed, suggesting an indirect mode of action (de Ruiter et al. 1995). A later study revealed that PKA activation with forskolin resulted in dephosphorylation of the AR at certain serine residues. In contrast with previous studies, dephosphorylation stimulated by forskolin treatment resulted in decreased AR transcriptional activity and reduced ligand binding (Blok et al. 1998). An in vivo study of AR-P revealed that in the absence of androgens, both isoforms (AR and AR-P) were present, but upon stimulation with androgens, the intensity of the phosphorylated form was increased whereas upon treatment with forskolin the AR-P isoform was depleted. When both androgens and forskolin were applied together, androgen-induced phosphorylation of the AR was inhibited (Wang \& Fondell 2001). In the absence of androgens, PKA activates the AR (Gioeli et al. 2002), an effect that can be inhibited by bicalutamide and flutamide and is believed to be a consequence of increased nuclear AR levels (Nazareth \& Weigel 1996).

DNA-PK has also been suggested to phosphorylate the AR hinge region (Konno et al. 1996) within a consensus site at Ser656 (Shank et al. 2008). It is suggested that DNA-PK might play a role in the nuclear export of the AR by the double-stranded DNA-dependent pathway. Furthermore, mutation of Ser578 inhibits the interaction with $\mathrm{Ku} \mathrm{70/80}$ and nuclear retention is promoted with hypophosphorylation at Ser515 (Ponguta et al. 2008). Indeed, AR-P was found to be the rate-limiting step in nuclear export (Shank et al. 2008).

\section{AR-P under androgen-depleted conditions}

Akt binds and phosphorylates AR at Ser213 (Wen et al. 2000) and Ser790 (Wen et al. 2000) under androgen-independent conditions. Upon mutation of these sites, PTEN, which inhibits Akt activity, can still inhibit AR, suggesting that neither p-Ser213 nor p-Ser790 is solely responsible for PTEN-mediated AR inhibition (Nan et al. 2003). Mutation of Ser213 also prevents Akt-mediated degradation of the AR, suggesting that this residue plays a role in AR turnover (Shank et al. 2008). Ser213 can also be phosphorylated by Akt in response to IGF1 (Lin et al. 2003) to result in receptor inhibition, probably by inhibiting coregulator interactions (Lin et al. 2001a). Similarly, IGF1 stimulation in skeletal muscle cells results in increased AR protein and transcript levels and enhanced p-Ser213 (Kim \& Lee 2009) via Akt (Lee 2009) to promote AR nuclear translocation in the absence of androgens (Kim \& Lee 2009). Interestingly, overexpression of caveolin 1, a co-activator of AR, is associated with increased phosphorylation of Ser213 (Bryant et al. 2011). A phosphospecific antibody has now been developed against p-Ser213, which revealed that the appearance of this modification in response to androgens depends on exactly which androgen is used. R1881 (a synthetic androgen) and DHT can promote p-Ser213 but testosterone has a very weak ability to do this. It is also suggested that a conformational change is required to expose this residue and enable phosphorylation (Taneja et al. 2005). The effects of Akt on AR do appear to depend on the number of times cell lines have been passaged; for example, in low passage LNCaP cells Akt inhibits AR, while in high passage cells Akt can activate the AR (Lin et al. 2003), which might explain why different functional outcomes are being observed. Upon comparing matched hormone-sensitive and refractory clinical samples of PC in terms of AR-P (Ser213) and the Akt signalling pathway, positive associations between expression and decreased time to death, time to relapse and survival were found (McCall et al. 2008). GSK-3 $\beta$, which is inhibited by Akt-mediated phosphorylation, also mediates AR-P but inhibits transcriptional activity by impeding the interaction between the $\mathrm{N}$ and $\mathrm{C}$ terminal regions, without affecting localisation or stability (Salas et al. 2004, Wang et al. 2004). Furthermore, PKA, Akt and MAPK inhibit GSK-3 $\beta$, which may explain some of the proposed indirect effects of 
these kinases on AR-P. Akt-mediated phosphorylation of the $A R$ is not responsible for the synergy observed for AR and Akt in the progression of tumours to relapse following androgen ablation therapy (Xin et al. 2006).

At reduced androgen levels, EGF can activate the AR by phosphorylating Ser515 (Ponguta et al. 2008), which can influence phosphorylation of Ser650; however, this residue does not play a role in regulating the function of the AR (Wong et al. 2004). In conjunction with p-Ser515, p-Ser578 is also required for IGF1-induced AR activation at reduced androgen levels (Ponguta et al. 2008). Upon mutation of Ser578, EGF can no longer result in an AR-mediated transcriptional response. EGF, and more noticeably forskolin treatment, can stimulate p-Ser650 at suboptimal concentrations of androgens (Gioeli et al. 2002). Similar to Ser256 and Ser118 (Kemppainen et al. 1992), Ser650 is a candidate for casein kinase 2 (CK2)-mediated phosphorylation, with stress signalling, MKK4, JNK, ERK1 and p38 being able to enhance p-Ser650 (Gao et al. 2004). One study found that phosphorylation of Ser650 has no effect on AR function (Wong et al. 2004), but other studies found that mutation of Ser650 decreased transcription by about 30\% (Zhou et al. 1994) and reduced nuclear export (Gioeli et al. 2006). Consistent with this, SNARE1, a protein that translocates AR from the nucleus to the cytoplasm and promotes p-Ser650, is involved in C-terminal HSP-interacting protein (CHIP) binding (E3 ubiquitin (Ub) ligase; Rees et al. 2006) and AR-Ub (Narayanan et al. 2010), suggesting that p-Ser650 down-regulates AR activity.

IKK and IKK2 have recently been shown to phosphorylate the AR in vitro, consistent with the IKK inhibitor BMS345541 being able to reduce AR-P in vivo (Jain et al. 2012), indicating crosstalk with yet another pathway and further demonstrating the increasing complexity of AR signalling.

\section{$A R-P$ and disease}

Suggesting a role in a more aggressive disease state, nonliganded activation of the AR can feature enhanced AR-P. For example, overexpression of $\mathrm{Her} 2 / \mathrm{Neu}$ results in elevated AR-P levels in AR-transfected DU145 cells (Sugita et al. 2004), IL6 activates AR via MAPK and Src (Ueda et al. 2002) and the activation of the CXCL12/CXCR 4 axis can increase PI3K-dependent AR-P, all in the absence of androgens (Kasina \& Macoska 2012). Furthermore, neuropeptides can influence AR-P, which is likely important in PC due to the occurrence of a neuroendocrine phenotype within some cells. This is further emphasised by observations that AR-P and increased AR activity are only seen in combination with very low androgen levels. This process appears to be dependent on PKC, PKA and MAPK, as revealed by use of specific inhibitor molecules (Dai et al. 2002). There is also a precedent that mutations within the AR can result in novel phosphorylation sites with functional outcomes, for example a missense mutation within exon 1 at $\operatorname{Arg} 405$ to a serine residue. However, in this case, the AR is less active than the
WT molecule as the PTM interferes with the binding of p300 (Lagarde et al. 2012).

Dysregulated AR-P at numerous sites has been implicated in PC development and progression. For example, Ser292 can be phosphorylated by Aurora A kinase, which is frequently overexpressed in numerous cancers, including PC, to promote cell survival, phosphorylation-dependent transactivation and PSA induction in the presence or absence of androgens (Shu et al. 2010). One of the best-characterised sites is Ser81, where p-Ser81 is increased in carcinoma compared with normal tissue (Li et al. 2006). P-Ser81 is inhibited by the topoisomerase inhibitor camptothecin, which results in decreased AR activity as a result of reduced androgen binding and nuclear translocation (Liu et al. 2010a). Androgen-independent PC cell line models have reported increased levels of p-Ser81 (Hsu et al. 2011), with AR stabilisation (Golsteyn et al. 1989, Faus \& Haendler 2008) and regulation of promoter specificity (Lee et al. 2007) being described as functional outcomes. Ser81 phosphorylation occurs in the nucleus, similar to Ser256 and Ser308 (Kesler et al. 2007), $\sim 4$ h post-androgen stimulation, suggesting that this residue is not responsible for enhancing nuclear translocation or DNA binding; hence, rapidly induced genes do not require this phosphorylation event (Chen et al. 2006). P-Ser81 can also be induced by activation of cells with conditioned media from stromal cells, indicating that this modification can play a role in stromal-epithelial interaction (Shigemura et al. 2009). Enzymes responsible for p-Ser81 include CDK9 (Gordon et al. 2010), CDK5 (Hsu et al. 2011) and CDK1 (Chen et al. 2012). Furthermore, Src can enhance p-Ser81 in a ligand-independent manner upon exposure to hepatitis B virus (HBV) viral factors (Chiu et al. 2007). P-Ser81 increases during mitosis when CDK1 is active, and inhibition of CDK1 and CDK9 results in decreased p-Ser81 while inhibiting AR chromatin binding and transcriptional activity (Chen et al. 2012). Mutation of two phenylalanine residues (Phe582 and Phe583) within the DNA recognition helix, which is seen in androgen insensitivity syndrome, results in hypophosphorylation at Ser81. This mutant AR localises in sub-nuclear foci with both CBP and glutamate receptor interacting protein 1 in the presence of androgen, suggesting that p-Ser81 occurs after nuclear localisation, ligand binding and interaction with $\mathrm{CBP}$ and other co-activators (Black et al. 2004).

\section{Tyrosine phosphorylation}

For many years, tyrosine phosphorylation of the AR remained undiscovered partly due to the fact that DHT cannot stimulate this PTM but EGF, Heregulin (HRG), IL6, FBS (Guo et al. 2006) and Etk can (Dai et al. 2010). Using mass spectrometry, p-Tyr534 was identified (Guo et al. 2006) and subsequently verified (Kraus et al. 2006). Interestingly, AR mutations at this site cannot be activated by EGF but they can still be activated by DHT, although are unresponsive to lower DHT concentrations. Codon switch experiments 
demonstrated that this phosphorylation event is required for PSA induction at low levels of DHT or in response to growth factor stimulation. Furthermore, Tyr534-mutant AR is not stimulated to translocate to the nucleus by Src activation (Guo et al. 2006). The scaffold protein GNB2L1 (RACK1), which interacts with the AR to facilitate ligand-independent AR nuclear translocation (Rigas et al. 2003), can also modulate AR tyrosine phosphorylation and its interaction with $\mathrm{Src}$ (Kraus et al. 2006). Tyr534 phosphorylation is increased in refractory xenograft models and is present in refractory human samples of PC. The mechanism by which this modification results in the observed functional outcomes is unclear, but a conformational change, which leads to improved ligand binding capabilities, has been suggested (Guo et al. 2006). A further two p-Tyr sites have since been documented: Tyr267 and Tyr363. Both sites are phosphorylated in response to HRG via Ack1 (cdc42-associated tyrosine kinase). Tyr267 appears to be the dominant functional site as mutation studies demonstrated that, whereas mutation of Tyr363 can inhibit AR activity, mutation of Tyr267 completely abolished HRG-stimulated AR activation (Mahajan et al. 2007). EGF and Gas6 can also result in Tyr267 phosphorylation (Liu et al. 2010b). Anti-androgens have no effect on tyrosine phosphorylation at 267 (Mahajan et al. 2010); however, inhibition can be achieved using Dasatinib, a Src and Ack1 inhibitor (Liu et al. 2010b). The AR isoform, AR8, has recently been identified. This isoform is membrane bound via two palmitoylation sites. Upon overexpression, increased Tyr-P of AR is observed alongside enhanced interactions between Src and EGFR and AR and EGFR (Yang et al. 2011a).

The glycoprotein precursor, prosaposin, is amplified in PC and is expressed at high levels in metastatic androgeninsensitive cancers where it stimulates growth, migration and invasion. Treatment of LNCaP cells with prosaposin resulted in increased Ser81 phosphorylation but had no effect on serine phosphorylation in LNCaP-AI or prostate stromal cells. However, when stromal cells were treated with either DHTor saposin C, an increased AR tyrosine phosphorylation was observed (Koochekpour et al. 2008).

\section{AR phosphatases}

Phosphorylation of the AR is a reversible process. Currently, only two protein phosphatases have been described to interact with and dephosphorylate the AR. Protein phosphatase 2A (PP2A) was the first enzyme to be identified to bind to ligand-activated AR and result in dephosphorylation at multiple sites (Table 3; Lin et al. 2002, Yang et al. 2005, 2007). Based on the sites, which are dephosphorylated, PP2A can result in enhanced AR stability and transcriptional activity. In addition, inhibition of PP2A maintains ligandindependent phosphorylation (Bhardwaj et al. 2011), which could be explained by dephosphorylation of Ser94, which is constitutively phosphorylated. A second phosphatase, PP1, has been shown to dephosphorylate Ser650 to result in enhanced AR levels, transcriptional activity and nuclear localisation (Chen et al. 2009). As mentioned previously, Ser650 and Ser662 can be dephosphorylated in response to PKA stimulation by forskolin, resulting in decreased AR transcriptional activity and reduced ligand binding (Blok et al. 1998). The proteoglycans, Decorin (Hu et al. 2009), bicalutamide and estramustine can also reduce the levels of AR-P (Wang et al. 1999a,b); however, some anti-androgens can induce AR-P levels and enhance AR nuclear levels, although whether the increased AR-P is either cause or consequence is not apparent. In comparison to phosphorylation, dephosphorylation is understudied. With the commercialisation of kinase and phosphatase siRNA screens, it will only be a matter of time before a plethora of novel AR phosphatases are identified with characterisation of their cellular effects. However, due to the complexity of phosphorylation sites and stimuli, this will not be an easy task. Furthermore, while there is evidence that a number of phosphorylation sites can influence each other, it will be interesting to see how this idea develops and whether another layer of complexity can be added to this signalling pathway.

\section{Ubiquitination of the AR}

$\mathrm{Ub}$, a 76 amino acid protein with a molecular mass of $\sim 8.5 \mathrm{kDa}$, is highly conserved and expressed in all tissues. Ubiquitination is the enzymatic process by which one or more Ub proteins becomes attached to another protein via the carboxylic acid group of the C-terminal glycine residue within activated forms of the protein. This process is catalysed by a series of enzymes, which function in an ordered sequence of events. First, an E1 enzyme functions to prepare the $\mathrm{Ub}$ moiety for protein attachment. An E2 enzyme then functions to conjugate the $\mathrm{Ub}$ to lysine residues within the target protein and thirdly an E3 Ub ligase provides specificity for the protein being targeted (Hicke 2001, Kerscher et al. 2006, Ande et al. 2009). Ubiquitination is an important mechanism by which the cell regulates the turnover of proteins; however, it can also function as a signalling moiety to affect functional outcomes of signalling pathways.

The downstream consequences of protein ubiquitination depend on the type of modification. For example, monoubiquitination vs poly-ubiquitination or variant chains formed through one of seven lysine residues in $\mathrm{Ub}$, e.g. Lys 48 vs Lys63 chains. Generally, poly-ubiquitination linked to Lys48 signals for the protein to be degraded by the proteasome, but poly-ubiquitination at Lys63 can indicate other processes including DNA damage sensing and repair, receptor internalisation, vesicular transport and signal transduction. The function of chains derived from other lysine sites in $\mathrm{Ub}$ (K6, K11, K27, K29 and K33) are less well characterised.

MDM2 was the first E3 Ub ligase identified for the AR (Lin et al. 2002). More recently, other E3 ligases have been identified including CHIP (Chymkowitch et al. 2011) and 
RNF6 (Xu et al. 2009). The RNF6 E3 ligase can promote poly-Ub of AR similar to MDM2, but it can also promote AR mono-Ub (Chymkowitch et al. 2011). AR-Ub on the promoters of androgen-responsive genes is thought to function to clear the promoter ready for a subsequent round of transcription.

A number of proteins have been described to regulate this PTM. The chaperone protein, HSP27, can prevent MDM2-mediated AR-Ub by associating with the AR in response to androgen stimulation (Zoubeidi et al. 2007). Tumour susceptibility gene 101 (TSG101) can increase AR-mediated transcription, which coincides with increased mono-ubiquitination of ligand-bound AR while having no significant impact on the stability of the AR itself. It is thought that TSG101 functions by preventing polyubiquitination rather than stimulating mono-ubiquitination (Burgdorf et al. 2004).

Interestingly, $\mathrm{AR}-\mathrm{P}$ is a requisite for MDM2-mediated ubiquitination, and AR-P mutants are more stable than WT AR. A mechanism was proposed whereby Akt is activated by ligands including IGF1 or IL6 to result in the phosphorylation and subsequent activation of MDM2 concurrently with AR-P. This in turn permits MDM2-mediated AR-Ub to target AR to the proteasome for degradation (Lin et al. 2002). Phosphorylation of AR at Ser515 is required for AR-MDM2 association and subsequent ubiquitination. However, when this phosphorylation cannot occur and MDM2 fails to interact, CHIP is recruited to facilitate interaction with the proteasomal machinery (Chymkowitch et al. 2011). A later study demonstrated that HDAC1 was also present in a complex with $\mathrm{AR}$ and MDM2 at androgen-regulated promoters where it can attenuate AR transcriptional activity. Furthermore, AR poly-Ub is androgen dependent and can be attenuated by the lysine acetyltransferase and AR co-activator Tip60 (KAT5; Gaughan et al. 2005).

Proposed sites of ubiquitination are within the KLKK motif due to the dependency on deacetylation. However, poly-Ub at Lys845 and Lys847 incorporating Lys6 and/or Lys 27 chains catalysed by the E3 Ub ligase, RNF6, has been reported. This modification functions as a binding site for other co-activator proteins, e.g. ARA54 (Xu et al. 2009). Interestingly, this is the first reported incidence of $A R$ poly-Ub to enhance transcriptional activity rather than result in proteasomal degradation. RNF6 can facilitate AR-mediated transcription at a subset of genes that does not include PSA and transmembrane protease, serine 2 (TMPRSS2), but it can still modulate AR function under androgen-deprived conditions (Xu et al. 2009).

Deubiquitinase (DUB) enzymes are responsible for the removal of $\mathrm{Ub}$ moieties from proteins. They function by cleaving the Ub modification at Gly76. This process can have multiple outcomes, for example generating free $\mathrm{Ub}$ protein that can be reattached to another protein, or reversing proteasomal targeting. In 2005, USP10 was identified as the first DUB to co-activate the AR, although direct AR deubiquitination was not investigated in this study (Faus et al.
2005). USP26 was also identified by siRNA screening, as a DUB that can interact with AR in the nucleus and modulate $\mathrm{AR}-\mathrm{Ub}$ in a cell line-specific and context-dependent manner. Interestingly, this study did not identify USP10 as an AR regulator (Dirac \& Bernards 2010). More recently, USP10 was found to deubiquitinate chromatin proteins at AR-regulated genes in response to androgens to enable transcriptional activation. Moreover, when USP10 levels are reduced, the levels of $\mathrm{AR}$ remain unchanged suggesting that USP10 functions as an AR co-activator but does not focus its enzymatic activity towards the AR itself (Draker et al. 2011). Similarly, USP22 co-activates the AR without altering AR levels; however, AR-USP22 interaction has only been described in the absence of androgens (Zhao et al. 2008).

\section{AR-sumoylation}

Sumoylation is the process by which small Ub-like modifier (SUMO) is added to a protein (Gareau \& Lima 2010, Wilkinson \& Henley 2010). There are three members of the SUMO protein family: SUMO1, SUMO2 and SUMO3. All these proteins are strongly conserved through evolution, indicating their importance in cellular mechanisms. The process by which the SUMO moiety is added to the target protein is very similar to that of the Ub system. The process requires an E1 activating enzyme, an E2 conjugating enzyme and an E3 ligating enzyme. The E1 activating enzyme consists of two subunits, Aos1 and Uba2, that show homology with the yeast activating enzyme Uba1, for Ub substrate (Johnson et al. 1997). In this first step in the pathway, the Gly-Gly residues are exposed on the C-terminus of SUMO, then a thiol ester adduct is formed between $\mathrm{Uba} 2$ and SUMO in an ATP-dependent process. The only E2 conjugating enzyme discovered to date is Ubc9 (Poukka et al. 2000). Finally, the E3 ligase enzyme attaches the SUMO to the protein of interest. Currently, there have been three types of E3 discovered. The first is the protein inhibitor of activated STAT (PIAS) family of proteins, the second is RanBP2 (localised to the nuclear pore complex) and the third is Pc2 (component of the polycomb protein complexes). The function of sumoylation is thought to determine cellular localisation, for example RanGAP1 is located in the cytoplasm but upon sumoylation is relocated to the nuclear envelope and, in some cases, can regulate transcriptional activity. Furthermore, sumoylation has been suggested as a protective mechanism to prevent structural alterations to proteins in response to cellular stress (Mukherjee et al. 2009). It has also been suggested that sumoylation may compete with the ubiquitination process as quite often the same residues within proteins are targeted by both pathways.

AR-sumoylation (AR-Su) was first described in 2000 after the SUMO conjugating enzyme, Ubc9, was found to interact with the AR to result in increased transcriptional activity (Poukka et al. 2000). The consensus sequence for protein sumoylation, (I/L/V)-K-X-D/E, was detected twice within 
the AR protein. AR-Su occurs within the N-terminal domain of the protein at Lys386 predominantly and at Lys520 to a reduced extent. This process is enhanced in the presence of ligand, which was thought to be a result of the increased levels of AR within the nucleus where Ubc9 resides (Poukka et al. 2000). However, it has since been noted that constitutively nuclear apo-AR (unliganded AR) or antagonistbound AR are only weakly sumoylated compared with agonist-bound AR (Kaikkonen et al. 2009). Sumoylation of $\mathrm{AR}$ at these highly conserved SUMO-acceptor sites results in negative regulation of the AR. It has been demonstrated that sumoylation within the $\mathrm{N}$ terminal domain of the $\mathrm{AR}$ impairs the intramolecular interaction with the ligand-binding domain, which is required for efficient transcriptional activation (Kaikkonen et al. 2009).

Interestingly, the increased transcriptional activity detected following overexpression of Ubc9 is not dependent on its enzymatic activity, suggesting that a more complicated chain of events is involved (Kaikkonen et al. 2009). Furthermore, upon mutation of the SUMO-accepting sites within the AR, greater transcriptional activity is observed, suggesting that $\mathrm{AR}-\mathrm{Su}$ is in fact an inhibitory process, similar to sumoylation of c-Jun. This may be expected as sumoylation sites are within the $\mathrm{N}$ terminal region, which is involved in the intramolecular interaction with the LBD upon hormone binding. Therefore, the addition of any large moieties to this region may interfere with this critical process. Furthermore, sumoylation is thought to result in the recruitment of co-repressors. For example, sumoylated p300 recruits HDAC6 while sumoylated ELK1 recruits HDAC2. This is indeed the case for AR where Daxx has recently been described as a SUMO-reader protein, which interacts with the AR in a sumoylation-dependent manner to inhibit DNA binding (Shih et al. 2007).

Early studies of AR-Su focused on the addition of SUMO1 to the AR, but later studies also demonstrated that SUMO3 and SUMO2 can function as AR regulators. However, in contrast to SUMO1, which inhibits AR activity, SUMO2 and -3 strongly enhance AR transcriptional activity in $\mathrm{LNCaP}$ cells. This differs from their effect on AR activity in primary prostate epithelial cells, where SUMO3 has a weak negative effect on AR activity, suggesting that effects are dependent on cell type and the cellular background. Interestingly, the sites of AR-Su and the ligase activity were found to be independent for the effects (Zheng et al. 2006).

HDAC4 can promote AR-Su, suggesting that it may function as an E3 ligase, similar to activity of other HDACs for other proteins. As HDAC4 is itself a target of sumoylation, it has been suggested that a sumoylation cascade may take place, yet a SUMO-deficient HDAC4 can still promote AR-Su (Yang et al. 2011b).

The E2 enzyme, Ubc9, provides substrate specificity and no other factors are required for it to function. Ubc9 has been found to interact with at least five nuclear receptors including the AR, where it can stimulate transcriptional activity. Interestingly, upon mutation of the cysteine residue to which SUMO1 binds, Ubc9 can still enhance AR transcriptional activity. It is thought that $\mathrm{Ubc} 9$ interaction with other proteins via its C terminus, specifically residues 151-158, is important for AR activation (Chang et al. 2007).

The inhibitors of activated STAT (PIAS) family of proteins are important $\mathrm{E} 3$ ligase enzymes in the sumoylation pathway. There are five members of the family, $-\mathrm{x} \alpha,-\mathrm{x} \beta,-\mathrm{y},-1$ and -3 . PIASx $\boldsymbol{\alpha}$ and PIAS1 can function as E3 enzymes for the AR; however, PIAS3, $-\mathrm{y}$ and $-\mathrm{x} \beta$ do not. Furthermore, PIAS interaction with the E2, Ubc9, is necessary for E3 ligase activity (Nishida \& Yasuda 2002).

The E3 protein PIASx $\alpha$ has been found to interact with the AR to modulate its activity, for which its E3 ligase activity and AR SUMO acceptor sites are essential. Additionally, this protein interacts with $\mathrm{Ubc} 9$ and SUMO1 and has been found to enhance the in vitro sumoylation of $\mathrm{AR}$ and c-Jun (Kotaja et al. 2002). As PIAS is a nuclear protein, the AR must translocate to the nucleus to be sumoylated, an idea that is supported by the observation that AR ligand binding is required in order for sumoylation to occur (Nishida \& Yasuda 2002).

Interestingly, PIAS1 and PIASx $\alpha$ can have differing effects on AR activity depending on the presence of SUMO1. When SUMO1 is present, AR activity is repressed, but in the absence of SUMO1, PIASx $\alpha$ and to a lesser extent PIAS1 can activate the AR (Zheng et al. 2006).

PIASy can also repress the transcriptional activity of the AR, yet it plays no role in AR-Su. This protein binds the AR DBD via its RING finger-like domain; however, even in the absence of its E3 ligase activity and mutation of the AR SUMO acceptor sites, it can still inhibit the transcriptional activity of the AR. Within the PIASy protein, there are two repression domains, RD1 and RD2, of which only RD1 is required for inhibition of the AR. RD1 has been shown to bind to HDAC1 and HDAC2, two proteins that have been previously shown to inhibit AR activity via their enzymatic activity (Gaughan et al. 2005). In the case of PIASy, HDAC activity of these two proteins is required in order for PIASy to inhibit AR transcriptional activity (Gross et al. 2004).

A PIAS-like protein termed, human zinc finger containing, MIZ1, PIAS-like protein on chromosome 10 (hZIMP10) has also been found to interact with the AR specifically in comparison with other steroid receptors. This particular protein has been found to reside at cell cycle-regulated DNA replication foci during $\mathrm{S}$ phase, suggesting a role for this protein in the replication process. hZIMP10, like PIAS1 and PIASx $\alpha$, can enhance the sumoylation of the AR and therefore the authors suggested that there may be a role for the AR and SUMO1 in DNA replication and chromatin modification (Sharma et al. 2003). From the same laboratory, a homologue of hZIMP10 has been identified, hZIMP7. Similarly, this protein was found not only to associate with the $\mathrm{AR}$ and DNA replication foci, but also to interact with the SWI/SNF complex, further supporting a role in chromatin modification (Huang et al. 2005). 
AR-Su is a reversible process (Poukka et al. 2000) achieved by a family of SUMO proteases termed Sentrin/SUMOspecific proteases (SENPs). There are six described SENPs: $-1,-2,-3,-5,-6$ and -7 . SENP1 resides in the nucleus, whereas SENP2 is associated with the nuclear envelope. SENP3 and SENP5 are nucleolar and display a preference for SUMO-2/3. SENP6 and -7 are also nuclear but currently their function is unknown (Cheng et al. 2006).

SENP1 was the first of these proteases to be described as an enhancer of AR-mediated transcription, although its activity was not directed at the AR itself but towards its co-repressor protein HDAC1 to reduce its deacetylase activity (Cheng et al. 2004). However, a more recent study declared that intact SUMO acceptor sites are required on the AR for SENP1 to have its activating effect on the AR (Kaikkonen et al. 2009). Yet both studies clearly show that SENP1 can indeed desumoylate the AR. Furthermore, SENP1 has been found to be overexpressed in prostatic intraepithelial neoplasia (PIN) and PC, and transgenic mice overexpressing SENP1 in the prostate were found to have early PIN development (Cheng et al. 2006).

\section{AR PTMs and Kennedy's disease}

Early studies into the importance of the glutamine repeat sequence (CAG repeat) found that deletion of this region results in a single form of the AR being observed instead of a 110 and a $112 \mathrm{kDa}$ doublet, suggesting that the phosphorylation responsible for this doublet is unable to occur. Furthermore, if this repeat region is further expanded, the upshift was enhanced (Jenster et al. 1994). Increased CAG repeat length is also associated with an increased rate of Ser94 phosphorylation (Choong et al. 1998).

PKA activation and PKA inhibition have been found to inhibit and activate the activity of the AR respectively. Interestingly, following mutation of AR-Ac acceptor sites, manipulation of PKA activity had no effect on AR activity (Fu et al. 2004).

Phosphorylation of Ser515 has been found to be critical in Kennedy's disease. In this disease, the AR has an extended N-terminal polyglutamine (CAG) tract, which leads to proteolytic cleavage resulting in cell death. This expansion results in activation of three kinase pathways: ERK, p38 and SAPK/JNK, suggesting that phosphorylation could be important. Upon mutation of the Ser515 residue to an alanine, AR-induced cell death and cleavage products were reduced, suggesting that Ser515 phosphorylation promotes caspase 3-mediated AR cleavage to yield the cytotoxic AR fragments (LaFevre-Bernt \& Ellerby 2003).

Akt, when activated by IGF1, can also phosphorylate AR with expanded polyglutamine tracts. Interestingly, using phosphorylation mimic mutants (Ser213 and Ser791), one study found that phosphorylation by Akt can reduce the toxicity of the mutant protein (Palazzolo et al. 2007) by enhancing the destruction of the AR via ubiquitination (Palazzolo et al. 2009).

Links between acetylation and the AR have also been demonstrated in the study of Kennedy's disease. In this disease, the presence of an expanded polyglutamine region causes the AR to aggregate. It appears that the expanded polyglutamine mutant $\mathrm{AR}$ protein binds $\mathrm{CBP}$, thereby quenching the acetylase activity, which can result in altered protein acetylation within the cell (McCampbell et al. 2001). Furthermore, ARs with expanded CAG repeats have been found to undergo PTM, including phosphorylation and acetylation, in the absence of ligand (Lieberman et al. 2002). Interestingly, AR mutated at both Lys632 and Lys633 was reported to misfold and aggregate, thereby mimicking the effects of an expanded CAG repeat, with effects on receptor trafficking also being reported. This double lysine mutant can also interact with HSP40 and -70 and the E3 ligase, CHIP, to result in inhibited proteasome function (Thomas et al. 2004).

Enhanced sumoylation of the AR has been suggested as a treatment for Kennedy's disease to alleviate the liganddependent misfolding and subsequent AR aggregation, which results in neurotoxicity. Sumoylation of the AR greatly reduces AR aggregation without altering the transcriptional activity or overall AR levels (Mukherjee et al. 2009).

\section{PTM interplay and future research}

The AR methyl and acetyl acceptor sites, Lys630 and Lys632, suggest that there will be crosstalk between these two types of modification. Many studies that investigate the effects of AR-Ac have used mutant AR proteins. Now that AR-Me has been described at the same sites as acetylation, it can no longer be concluded that all the effects seen are due to the lack of AR-Ac; perhaps some are due to lack of Me. One important observation is that acetylation appears to be important for AR translocation to the nucleus (Shiota et al. 2010) and Me should occur in the nucleus based on the cellular localisation of most methyltransferase enzymes, including Set 9 . Therefore, acetylation should precede Me upon stimulation with androgens. Furthermore, deacetylation will be required before Me. SIRT1 is a deacetylase enzyme that can repress DHTmediated AR expression by binding to and deacetylating AR. This deacetylation event has been found to be neuroprotective and can protect against proteotoxicity in Kennedy's disease (Montie et al. 2011). It can also reduce the AR $\mathrm{N} / \mathrm{C}$ terminal interaction and inhibit contact-independent cell growth. This particular deacetylase enzyme is a member of the class III deacetylase enzymes, which are dependent on NAD levels within the cell. Interestingly, it has been reported that there is an increase in lactate within cells during PC progression, which is predicted to inhibit the action of these deacetylase enzymes, resulting in enhanced AR function. It appears that AR Lys630 is more susceptible to SIRT1 (Fu et al. 2006), which is supported by Lys630Ala 
substitution also demonstrating reduced $\mathrm{N} / \mathrm{C}$ terminal interaction (Ko et al. 2011), raising the question as to whether acetylation and Me can functionally interact via the action of SIRT1. As AR-Me is not currently well documented, it may emerge that many other KMTs can methylate the AR. Furthermore, the role of demethylation has not been investigated at this stage. As many KDMs can influence AR activity, e.g. LSD1 and KDM4A, further research is required to elucidate whether $\mathrm{Me}$ is also a reversible process similar to other PTMs. It will be interesting to determine how a flux in Me state can be influenced by other PTMs such as acetylation and indeed how Me changes can affect other PTMs of the AR.

Functional relationships between acetylation and phosphorylation of the AR have been proposed. Efficient regulation of the $\mathrm{AR}$ by $\mathrm{AKT}$, PKA and JNK requires functional acetylation sites within the AR. Indeed, mutation of acetyl acceptor sites within the AR reduced the ability of the AR to become phosphorylated. Similarly, point mutations at phosphorylation sites reduced the ability of TSA to stimulate the AR, for example Ser94Ala results in decreased transactivation by p300 (Fu et al. 2004). Co-occurrence of phosphorylation and acetylation within the same protein is widely seen with the modifications occurring at interaction interfaces. As phosphorylation of Ser94 and Ser213 is stimulated by androgens similar to AR-Ac, functional interplay may be occurring here. Similarly, due to the identification of AR-Me sites being shared with AR-Ac sites, there may also be potential for interaction between phosphorylation and Me.
Sumoylation has been suggested as a competitor for ubiquitination as the same residues are often targeted within proteins. At present, there is no evidence to suggest that this is the case for AR. However, there is minimal information relating to $\mathrm{AR} \mathrm{Ub}$ sites, with the functional outcome and types of $\mathrm{Ub}$ modifications being poorly understood at present.

As mentioned previously, AR-P at Ser515 is required for MDM2-mediated AR-Ub. When Ser515 cannot be phosphorylated, the AR interacts with an alternative E3 ligase, CHIP (Chymkowitch et al. 2011). Association with CHIP can be promoted by AR-P at Ser650 to result in increased AR-Ub (Narayanan et al. 2010). Interestingly, Ser515 phosphorylation mediated by EGF at low androgen concentrations can influence phosphorylation of Ser650 (Wong et al. 2004). This would suggest that the AR would be less stable in response to this modification; however, phosphorylation at Tyr534 can be observed under these conditions to result in reduced AR-CHIP interaction and an increase in AR levels (DaSilva et al. 2009). Phosphorylation of Ser515 is reduced upon mutation of Ser578 to result in nuclear retention of the AR (Ponguta et al. 2008), which may be due to inhibition of MDM2-mediated AR-Ub at androgen-regulated genes.

In summary, this highlights the complexity of PTM interactions within one molecule to regulate its activity (Fig. 2). This will only increase in scale as all types of modification are better characterised in the coming years. Furthermore, with respect to the AR itself, the complexity of its regulation further emphasises its biological importance. Moreover, there is potential for PTMs on different proteins to

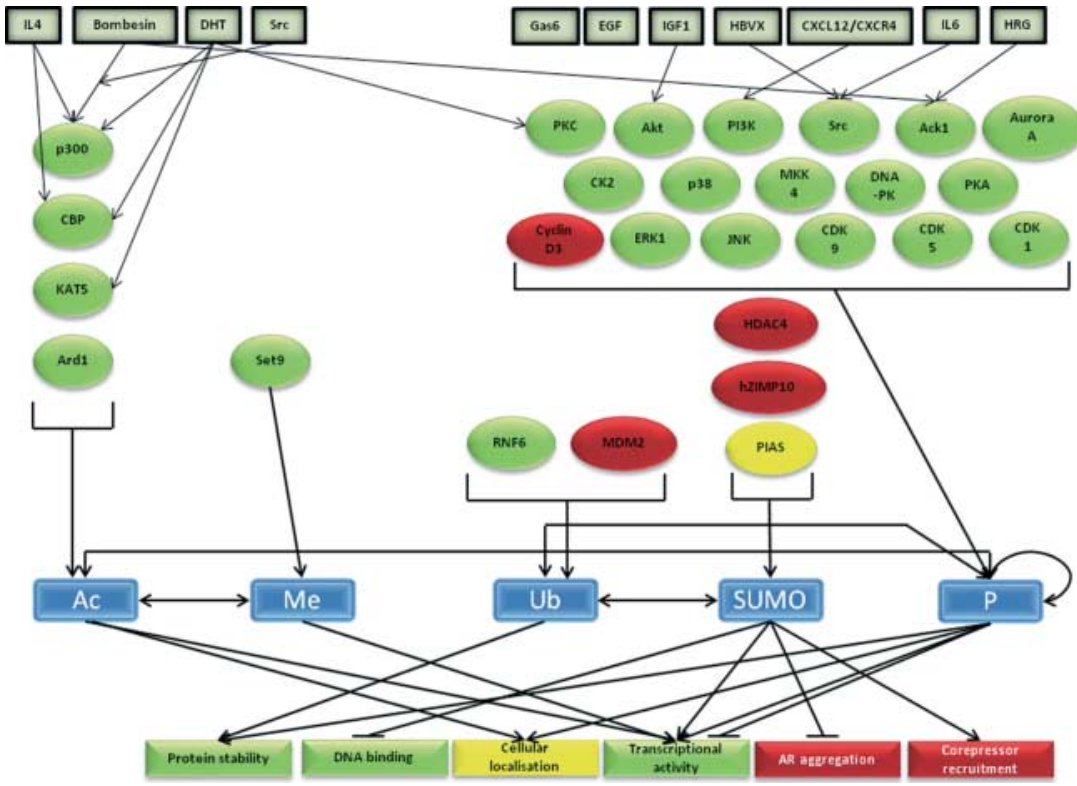

Figure 2 Summary of enzymes and molecules involved in regulation of androgen receptor (AR) post-translational modifications and their effects on AR function. The AR can be acetylated (Ac), methylated (Me), sumoylated (Su), ubiquitinated ( $\mathrm{Ub}$ ) and phosphorylated $(\mathrm{P})$ by a number of enzymes to have either positive effects on the AR (shown in green) or negative effects on the AR (shown in red). 
interact, an idea that is being developed between histone proteins and transcription factors, further expanding the complexity of this interaction pathway.

\section{Declaration of interest}

The authors declare that there is no conflict of interest that could be perceived as prejudicing the impartiality of the research reported.

\section{Funding}

This work was supported by The Prostate Cancer Charity (PG09-23) and Prostate Action (G2011-14).

\section{Acknowledgements}

The authors would like to thank Claudia Ryan-Munden for laboratory support.

\section{References}

Ai J, Wang Y, Dar JA, Liu J, Liu L, Nelson JB \& Wang Z 2009 HDAC6 regulates androgen receptor hypersensitivity and nuclear localization via modulating Hsp90 acetylation in castration-resistant prostate cancer. Molecular Endocrinology 23 1963-1972. (doi:10.1210/me.2009-0188)

Ande SR, Chen J \& Maddika S 2009 The ubiquitin pathway: an emerging drug target in cancer therapy. European Journal of Pharmacology 625 199-205. (doi:10.1016/j.ejphar.2009.08.042)

Beitel LK, Sabbaghian N, Alarifi A, Alvarado C, Pinsky L \& Trifiro M 1995 Characterization of normal and point-mutated human androgen receptors expressed in the baculovirus system. Journal of Molecular Endocrinology 15 117-128. (doi:10.1677/jme.0.0150117)

Bhardwaj A, Singh S, Srivastava SK, Honkanen RE, Reed E \& Singh AP 2011 Modulation of protein phosphatase $2 \mathrm{~A}$ activity alters androgen-independent growth of prostate cancer cells: therapeutic implications. Molecular Cancer Therapeutics 10 720-731. (doi:10.1158/1535-7163.MCT-10-1096)

Black BE, Vitto MJ, Gioeli D, Spencer A, Afshar N, Conaway MR, Weber MJ \& Paschal BM 2004 Transient, ligand-dependent arrest of the androgen receptor in subnuclear foci alters phosphorylation and coactivator interactions. Molecular Endocrinology 18 834-850. (doi:10.1210/me. 2003-0145)

Blok LJ, de Ruiter PE \& Brinkmann AO 1998 Forskolin-induced dephosphorylation of the androgen receptor impairs ligand binding. Biochemistry 37 3850-3857. (doi:10.1021/bi9724422)

Bryant KG, Camacho J, Jasmin JF, Wang C, Addya S, Casimiro MC, Fortina P, Balasubramaniam S, Knudsen KE, Schwarting R et al. 2011 Caveolin-1 overexpression enhances androgen-dependent growth and proliferation in the mouse prostate. International Journal of Biochemistry \& Cell Biology 43 1318-1329. (doi:10.1016/j.biocel.2011.04.019)

Burgdorf S, Leister P \& Scheidtmann KH 2004 TSG101 interacts with apoptosis-antagonizing transcription factor and enhances androgen receptor-mediated transcription by promoting its monoubiquitination. Journal of Biological Chemistry 279 17524-17534. (doi:10.1074/jbc. M313703200)

Chang YL, Huang CJ, Chan JY, Liu PY, Chang HP \& Huang SM 2007 Regulation of nuclear receptor and coactivator functions by the carboxyl terminus of ubiquitin-conjugating enzyme 9. International Journal of Biochemistry \& Cell Biology 39 1035-1046. (doi:10.1016/j.biocel. 2007.02.002)
Chen S, Xu Y, Yuan X, Bubley GJ \& Balk SP 2006 Androgen receptor phosphorylation and stabilization in prostate cancer by cyclin-dependent kinase 1. PNAS 103 15969-15974. (doi:10.1073/pnas.0604193103)

Chen S, Kesler CT, Paschal BM \& Balk SP 2009 Androgen receptor phosphorylation and activity are regulated by an association with protein phosphatase 1. Journal of Biological Chemistry 284 25576-25584. (doi:10.1074/jbc.M109.043133)

Chen S, Gulla S, Cai C \& Balk SP 2012 Androgen receptor serine 81 phosphorylation mediates chromatin binding and transcriptional activation. Journal of Biological Chemistry 287 8571-8583. (doi:10.1074/jbc.M111. 325290)

Cheng J, Wang D, Wang Z \& Yeh ET 2004 SENP1 enhances androgen receptor-dependent transcription through desumoylation of histone deacetylase 1. Molecular and Cellular Biology 24 6021-6028. (doi:10.1128/ MCB.24.13.6021-6028.2004)

Cheng J, Bawa T, Lee P, Gong L \& Yeh ET 2006 Role of desumoylation in the development of prostate cancer. Neoplasia 8 667-676. (doi:10.1593/neo. 06445)

Chiu CM, Yeh SH, Chen PJ, Kuo TJ, Chang CJ, Yang WJ \& Chen DS 2007 Hepatitis B virus $\mathrm{X}$ protein enhances androgen receptor-responsive gene expression depending on androgen level. PNAS 104 2571-2578. (doi:10.1073/pnas.0609498104)

Choi KC, Park S, Lim BJ, Seong AR, Lee YH, Shiota M, Yokomizo A, Naito S, Na Y \& Yoon HG 2011 Procyanidin B3, an inhibitor of histone acetyltransferase, enhances the action of antagonist for prostate cancer cells via inhibition of p300-dependent acetylation of androgen receptor. Biochemical Journal 433 235-244. (doi:10.1042/BJ20100980)

Choong CS, Kemppainen JA \& Wilson EM 1998 Evolution of the primate androgen receptor: a structural basis for disease. Journal of Molecular Evolution 47 334-342. (doi:10.1007/PL00006391)

Chymkowitch P, Le May N, Charneau P, Compe E \& Egly JM 2011 The phosphorylation of the androgen receptor by TFIIH directs the ubiquitin/proteasome process. EMBO Journal 30 468-479. (doi:10.1038/ emboj.2010.337)

Dai J, Shen R, Sumitomo M, Stahl R, Navarro D, Gershengorn MC \& Nanus DM 2002 Synergistic activation of the androgen receptor by bombesin and low-dose androgen. Clinical Cancer Research 8 2399-2405.

Dai B, Chen H, Guo S, Yang X, Linn DE, Sun F, Li W, Guo Z, Xu K, Kim O et al. 2010 Compensatory upregulation of tyrosine kinase Etk/BMX in response to androgen deprivation promotes castration-resistant growth of prostate cancer cells. Cancer Research 70 5587-5596. (doi:10.1158/00085472.CAN-09-4610)

DaSilva J, Gioeli D, Weber MJ \& Parsons SJ 2009 The neuroendocrinederived peptide parathyroid hormone-related protein promotes prostate cancer cell growth by stabilizing the androgen receptor. Cancer Research 69 7402-7411. (doi:10.1158/0008-5472.CAN-08-4687)

Dirac AM \& Bernards R 2010 The deubiquitinating enzyme USP26 is a regulator of androgen receptor signaling. Molecular Cancer Research $\mathbf{8}$ 844-854. (doi:10.1158/1541-7786.MCR-09-0424)

Draker R, Sarcinella E \& Cheung P 2011 USP10 deubiquitylates the histone variant H2A.Z and both are required for androgen receptor-mediated gene activation. Nucleic Acids Research 39 3529-3542. (doi:10.1093/nar/ gkq1352)

Faus H \& Haendler B 2006 Post-translational modifications of steroid receptors. Biomedicine \& Pharmacotherapy 60 520-528. (doi:10.1016/ j.biopha.2006.07.082)

Faus H \& Haendler B 2008 Androgen receptor acetylation sites differentially regulate gene control. Journal of Cellular Biochemistry 104 511-524. (doi:10.1002/jcb.21640)

Faus H, Meyer HA, Huber M, Bahr I \& Haendler B 2005 The ubiquitinspecific protease USP10 modulates androgen receptor function. Molecular and Cellular Endocrinology 245 138-146. (doi:10.1016/j.mce.2005.11.011) Fu M, Wang C, Reutens AT, Wang J, Angeletti RH, Siconolfi-Baez L, Ogryzko V, Avantaggiati ML \& Pestell RG 2000 p300 and p300/cAMPresponse element-binding protein-associated factor acetylate the androgen receptor at sites governing hormone-dependent transactivation. Journal of Biological Chemistry 275 20853-20860. (doi:10.1074/jbc.M000660200) 
Fu M, Wang C, Wang J, Zhang X, Sakamaki T, Yeung YG, Chang C, Hopp T, Fugua SA, Jaffray E et al. 2002 Androgen receptor acetylation governs trans activation and MEKK1-induced apoptosis without affecting in vitro sumoylation and transrepression function. Molecular and Cellular Biology 10 3373-3388. (doi:10.1128/MCB.22.10.3373-3388.2002)

Fu M, Rao M, Wang C, Sakamaki T, Wang J, Di Vizio D, Zhang X, Albanese C, Balk S, Chang C et al. 2003 Acetylation of androgen receptor enhances coactivator binding and promotes prostate cancer cell growth. Molecular and Cellular Biology 23 8563-8575. (doi:10.1128/MCB. 23.23.8563-8575.2003)

Fu M, Rao M, Wu K, Wang C, Zhang X, Hessien M, Yeung YG, Gioeli D, Weber MJ \& Pestell RG 2004 The androgen receptor acetylation site regulates CAMP and AKT but not ERK-induced activity. Journal of Biological Chemistry 279 29436-29449. (doi:10.1074/jbc.M313466200)

Fu M, Liu M, Sauve AA, Jiao X, Zhang X, Wu X, Powell MJ, Yang T, Gu W, Avantaggiati ML et al. 2006 Hormonal control of androgen receptor function through SIRT1. Molecular and Cellular Biology 26 8122-8135. (doi:10.1128/MCB.00289-06)

Gao S, Liu GZ \& Wang Z 2004 Modulation of androgen receptor-dependent transcription by resveratrol and genistein in prostate cancer cells. Prostate $\mathbf{5 9}$ 214-225. (doi:10.1002/pros.10375)

Gareau JR \& Lima CD 2010 The SUMO pathway: emerging mechanisms that shape specificity, conjugation and recognition. Nature Reviews. Molecular Cell Biology 11 861-871. (doi:10.1038/nrm3011)

Gaughan L, Logan IR, Cook S, Neal DE \& Robson CN 2002 Tip60 and histone deacetylase 1 regulate androgen receptor activity through changes to the acetylation status of the receptor. Journal of Biological Chemistry 277 25904-25913. (doi:10.1074/jbc.M203423200)

Gaughan L, Logan IR, Neal DE \& Robson CN 2005 Regulation of androgen receptor and histone deacetylase 1 by $\mathrm{Mdm} 2$-mediated ubiquitylation. Nucleic Acids Research 33 13-26. (doi:10.1093/nar/gki141)

Gaughan L, Stockley J, Wang N, McCracken SR, Treumann A, Armstrong K, Shaheen F, Watt K, McEwan IJ, Wang C et al. 2011 Regulation of the androgen receptor by SET9-mediated methylation. Nucleic Acids Research 39 1266-1279. (doi:10.1093/nar/gkq861)

Gibbs A, Schwartzman J, Deng V \& Alumkal J 2009 Sulforaphane destabilizes the androgen receptor in prostate cancer cells by inactivating histone deacetylase 6. PNAS 106 16663-16668. (doi:10.1073/pnas.0908908106)

Gioeli D \& Paschal BM 2012 Post-translational modification of the androgen receptor. Molecular and Cellular Endocrinology 352 70-78. (doi:10.1016/ j.mce.2011.07.004)

Gioeli D, Ficarro SB, Kwiek JJ, Aaronson D, Hancock M, Catling AD, White FM, Christian RE, Settlage RE, Shabanowitz J et al. 2002 Androgen receptor phosphorylation. Regulation and identification of the phosphorylation sites. Journal of Biological Chemistry 277 29304-29314. (doi:10.1074/jbc.M204131200)

Gioeli D, Black BE, Gordon V, Spencer A, Kesler CT, Eblen ST, Paschal BM \& Weber MJ 2006 Stress kinase signaling regulates androgen receptor phosphorylation, transcription, and localization. Molecular Endocrinology 20 503-515. (doi:10.1210/me.2005-0351)

Golsteyn EJ, Graham JS, Goren HJ \& Lefebvre YA 1989 Phosphorylation status of nuclear and cytosolic androgen receptors in the rat ventral prostate. Prostate 14 91-101. (doi:10.1002/pros.2990140203)

Golsteyn EJ, Goren HJ, Lehoux JG \& Lefebvre YA 1990 Phosphorylation and nuclear processing of the androgen receptor. Biochemical and Biophysical Research Communications 171 336-341. (doi:10.1016/0006291X(90)91398-C)

Gong J, Zhu J, Goodman OB Jr, Pestell RG, Schlegel PN, Nanus DM \& Shen R 2006 Activation of p300 histone acetyltransferase activity and acetylation of the androgen receptor by bombesin in prostate cancer cells. Oncogene 25 2011-2021. (doi:10.1038/sj.onc.1209231)

Gordon V, Bhadel S, Wunderlich W, Zhang J, Ficarro SB, Mollah SA, Shabanowitz J, Hunt DF, Xenarios I, Hahn WC et al. 2010 CDK9 regulates AR promoter selectivity and cell growth through serine 81 phosphorylation. Molecular Endocrinology 24 2267-2280. (doi:10.1210/me. 2010-0238)
Goueli SA, Holtzman JL \& Ahmed K 1984 Phosphorylation of the androgen receptor by a nuclear cAMP-independent protein kinase. Biochemical and Biophysical Research Communications 123 778-784. (doi:10.1016/0006291X(84)90297-3)

Gross M, Yang R, Top I, Gasper C \& Shuai K 2004 PIASy-mediated repression of the androgen receptor is independent of sumoylation. Oncogene 23 3059-3066. (doi:10.1038/sj.onc.1207443)

Gu W \& Roeder RG 1997 Activation of p53 sequence-specific DNA binding by acetylation of the p53 C-terminal domain. Cell 90 595-606. (doi:10.1016/S0092-8674(00)80521-8)

Guo Z, Dai B, Jiang T, Xu K, Xie Y, Kim O, Nesheiwat I, Kong X, Melamed J, Handratta VD et al. 2006 Regulation of androgen receptor activity by tyrosine phosphorylation. Cancer Cell 10 309-319. (doi:10.1016/j.ccr.2006.08.021)

Haelens A, Tanner T, Denayer S, Callewaert L \& Claessens F 2007 The hinge region regulates DNA binding, nuclear translocation, and transactivation of the androgen receptor. Cancer Research 67 4514-4523. (doi:10.1158/00085472.CAN-06-1701)

Harada N, Atarashi K, Murata Y, Yamaji R, Nakano Y \& Inui H 2011 Inhibitory mechanisms of the transcriptional activity of androgen receptor by resveratrol: implication of DNA binding and acetylation of the receptor. Journal of Steroid Biochemistry and Molecular Biology 123 65-70. (doi:10.1016/ j.jsbmb.2010.11.002)

Hicke L $2001 \mathrm{~A}$ new ticket for entry into budding vesicles-ubiquitin. Cell 106 527-530. (doi:10.1016/S0092-8674(01)00485-8)

Hsu FN, Chen MC, Chiang MC, Lin E, Lee YT, Huang PH, Lee GS \& Lin H 2011 Regulation of androgen receptor and prostate cancer growth by cyclin-dependent kinase 5. Journal of Biological Chemistry 286 33141-33149. (doi:10.1074/jbc.M111.252080)

Hu Y, Sun H, Owens RT, Wu J, Chen YQ, Berquin IM, Perry D, O'Flaherty JT \& Edwards IJ 2009 Decorin suppresses prostate tumor growth through inhibition of epidermal growth factor and androgen receptor pathways. Neoplasia 11 1042-1053.

Huang CY, Beliakoff J, Li X, Lee J, Sharma M, Lim B \& Sun Z 2005 hZimp7, a novel PIAS-like protein, enhances androgen receptor-mediated transcription and interacts with SWI/SNF-like BAF complexes. Molecular Endocrinology 19 2915-2929. (doi:10.1210/me.2005-0097)

Ikonen T, Palvimo JJ, Kallio PJ, Reinikainen P \& Janne OA 1994 Stimulation of androgen-regulated transactivation by modulators of protein phosphorylation. Endocrinology 135 1359-1366. (doi:10.1210/ en.135.4.1359)

Jain G, Voogdt C, Tobias A, Spindler KD, Moller P, Cronauer MV \& Marienfeld RB 2012 IkappaB kinases modulate the activity of the androgen receptor in prostate carcinoma cell lines. Neoplasia 14 178-189. (doi:10.1593/neo.111444)

Jenster G, de Ruiter PE, van der Korput HA, Kuiper GG, Trapman J \& Brinkmann AO 1994 Changes in the abundance of androgen receptor isotypes: effects of ligand treatment, glutamine-stretch variation, and mutation of putative phosphorylation sites. Biochemistry 33 14064-14072. (doi:10.1021/bi00251a015)

Johnson ES, Schwienhorst I, Dohmen RJ \& Blobel G 1997 The ubiquitinlike protein Smt3p is activated for conjugation to other proteins by an Aos1p/Uba2p heterodimer. EMBO Journal 16 5509-5519. (doi:10.1093/ emboj/16.18.5509)

Kaikkonen S, Jaaskelainen T, Karvonen U, Rytinki MM, Makkonen H, Gioeli D, Paschal BM \& Palvimo JJ 2009 SUMO-specific protease 1 (SENP1) reverses the hormone-augmented SUMOylation of androgen receptor and modulates gene responses in prostate cancer cells. Molecular Endocrinology 23 292-307. (doi:10.1210/me.2008-0219)

Kang HY, Huang KE, Chang SY, Ma WL, Lin WJ \& Chang C 2002 Differential modulation of androgen receptor-mediated transactivation by Smad3 and tumor suppressor Smad4. Journal of Biological Chemistry 277 43749-43756. (doi:10.1074/jbc.M205603200)

Karvonen U, Janne OA \& Palvimo JJ 2006 Androgen receptor regulates nuclear trafficking and nuclear domain residency of corepressor HDAC7 in a ligand-dependent fashion. Experimental Cell Research 312 3165-3183. (doi:10.1016/j.yexcr.2006.06.018) 
Kasina S \& Macoska JA 2012 The CXCL12/CXCR4 axis promotes ligandindependent activation of the androgen receptor. Molecular and Cellular Endocrinology 351 249-263. (doi:10.1016/j.mce.2011.12.015)

Kemppainen JA, Lane MV, Sar M \& Wilson EM 1992 Androgen receptor phosphorylation, turnover, nuclear transport, and transcriptional activation. Specificity for steroids and antihormones. Journal of Biological Chemistry 267 968-974.

Kerscher O, Felberbaum R \& Hochstrasser M 2006 Modification of proteins by ubiquitin and ubiquitin-like proteins. Annual Review of Cell and Developmental Biology 22 159-180. (doi:10.1146/annurev.cellbio.22. 010605.093503)

Kesler CT, Gioeli D, Conaway MR, Weber MJ \& Paschal BM 2007 Subcellular localization modulates activation function 1 domain phosphorylation in the androgen receptor. Molecular Endocrinology 21 2071-2084. (doi:10.1210/me.2007-0240)

Kim HJ \& Lee WJ 2009 Insulin-like growth factor-I induces androgen receptor activation in differentiating C2C12 skeletal muscle cells. Molecules and Cells 28 189-194. (doi:10.1007/s10059-009-0118-8)

Ko S, Ahn J, Song CS, Kim S, Knapczyk-Stwora K \& Chatterjee B 2011 Lysine methylation and functional modulation of androgen receptor by Set9 methyltransferase. Molecular Endocrinology 25 433-444. (doi:10.1210/ me.2010-0482)

Konno S, Hsieh TC, Wu JM, Chen Y, Chiao JW \& Mallouh C 1996 Growth control of human prostatic cancer cells by the phorbol ester TPA: possible involvement of protein kinases. Anticancer Research 16 1843-1849.

Koochekpour S, Lee TJ, Sun Y, Hu S, Grabowski GA, Liu Z \& Garay J 2008 Prosaposin is an AR-target gene and its neurotrophic domain upregulates AR expression and activity in prostate stromal cells. Journal of Cellular Biochemistry 104 2272-2285. (doi:10.1002/jcb.21786)

Kotaja N, Karvonen U, Janne OA \& Palvimo JJ 2002 PIAS proteins modulate transcription factors by functioning as SUMO-1 ligases. Molecular and Cellular Biology 22 5222-5234. (doi:10.1128/MCB.22.14.5222-5234. 2002)

Kraus S, Gioeli D, Vomastek T, Gordon V \& Weber MJ 2006 Receptor for activated $\mathrm{C}$ kinase 1 (RACK1) and Src regulate the tyrosine phosphorylation and function of the androgen receptor. Cancer Research 66 11047-11054. (doi:10.1158/0008-5472.CAN-06-0596)

Kuiper GG \& Brinkmann AO 1995 Phosphotryptic peptide analysis of the human androgen receptor: detection of a hormone-induced phosphopeptide. Biochemistry 34 1851-1857. (doi:10.1021/bi00006a005)

Kuiper GG, de Ruiter PE, Grootegoed JA \& Brinkmann AO 1991 Synthesis and post-translational modification of the androgen receptor in $\mathrm{LNCaP}$ cells. Molecular and Cellular Endocrinology 80 65-73. (doi:10.1016/03037207(91)90143-G)

Kuiper GG, de Ruiter PE, Trapman J, Boersma WJ, Grootegoed JA \& Brinkmann AO 1993 Localization and hormonal stimulation of phosphorylation sites in the $\mathrm{LNCaP}-$ cell androgen receptor. Biochemical Journal 291 95-101.

van Laar JH, Bolt-de Vries J, Zegers ND, Trapman J \& Brinkmann AO 1990 Androgen receptor heterogeneity and phosphorylation in human LNCaP cells. Biochemical and Biophysical Research Communications 166 193-200. (doi:10.1016/0006-291X(90)91930-Q)

van Laar JH, Berrevoets CA, Trapman J, Zegers ND \& Brinkmann AO 1991 Hormone-dependent androgen receptor phosphorylation is accompanied by receptor transformation in human lymph node carcinoma of the prostate cells. Journal of Biological Chemistry 266 3734-3738.

LaFevre-Bernt MA \& Ellerby LM 2003 Kennedy's disease. Phosphorylation of the polyglutamine-expanded form of androgen receptor regulates its cleavage by caspase- 3 and enhances cell death. Journal of Biological Chemistry 278 34918-34924. (doi:10.1074/jbc.M302841200)

Lagarde WH, Blackwelder AJ, Minges JT, Hnat AT, French FS \& Wilson EM 2012 Androgen receptor exon 1 mutation causes androgen insensitivity by creating a phosphorylation site and inhibiting melanoma antigen-A11 activation of N/C interaction-dependent transactivation. Journal of Biological Chemistry 287 10905-10915. (doi:10.1074/jbc.M111.336081)

Lee WJ 2009 Insulin-like growth factor-I-induced androgen receptor activation is mediated by the PI3K/Akt pathway in C2C12 skeletal muscle cells. Molecules and Cells 28 495-499. (doi:10.1007/s10059-009-0142-8)
Lee YH, Hong SW, Jun W, Cho HY, Kim HC, Jung MG, Wong J, Kim HI, Kim CH \& Yoon HG 2007 Anti-histone acetyltransferase activity from allspice extracts inhibits androgen receptor-dependent prostate cancer cell growth. Bioscience, Biotechnology, and Biochemistry 71 2712-2719. (doi:10.1271/bbb.70306)

Lee YH, Jung MG, Kang HB, Choi KC, Haam S, Jun W, Kim YJ, Cho HY \& Yoon HG 2008 Effect of anti-histone acetyltransferase activity from Rosa rugosa Thunb. (Rosaceae) extracts on androgen receptor-mediated transcriptional regulation. Journal of Ethnopharmacology 118 412-417. (doi:10.1016/j.jep.2008.05.006)

Lee SO, Chun JY, Nadiminty N, Lou W, Feng S \& Gao AC 2009 Interleukin4 activates androgen receptor through CBP/p300. Prostate 69 126-132. (doi:10.1002/pros.20865)

Lee YH, Kwak J, Choi HK, Choi KC, Kim S, Lee J, Jun W, Park HJ \& Yoon HG 2012 EGCG suppresses prostate cancer cell growth modulating acetylation of androgen receptor by anti-histone acetyltransferase activity. International Journal of Molecular Medicine 30 69-74.

Levy L, Wei Y, Labalette C, Wu Y, Renard CA, Buendia MA \& Neuveut C 2004 Acetylation of $\beta$-catenin by $\mathrm{p} 300$ regulates $\beta$-catenin-Tcf4 interaction. Molecular and Cellular Biology 24 3404-3414. (doi:10.1128/ MCB.24.8.3404-3414.2004)

Li Z, Szabolcs M, Terwilliger JD \& Efstratiadis A 2006 Prostatic intraepithelial neoplasia and adenocarcinoma in mice expressing a probasin-Neu oncogenic transgene. Carcinogenesis 27 1054-1067. (doi:10.1093/carcin/ bgi324)

Lieberman AP, Harmison G, Strand AD, Olson JM \& Fischbeck KH 2002 Altered transcriptional regulation in cells expressing the expanded polyglutamine androgen receptor. Human Molecular Genetics 11 1967-1976. (doi:10.1093/hmg/11.17.1967)

Lin HK, Yeh S, Kang HY \& Chang C 2001a Akt suppresses androgeninduced apoptosis by phosphorylating and inhibiting androgen receptor. PNAS 98 7200-7205. (doi:10.1073/pnas.121173298)

Lin MF, Lee MS, Zhou XW, Andressen JC, Meng TC, Johansson SL, West WW, Taylor RJ, Anderson JR \& Lin FF $2001 b$ Decreased expression of cellular prostatic acid phosphatase increases tumorigenicity of human prostate cancer cells. Journal of Urology 166 1943-1950. (doi:10.1016/S0022-5347(05)65725-4)

Lin HK, Wang L, Hu YC, Altuwaijri S \& Chang C 2002 Phosphorylationdependent ubiquitylation and degradation of androgen receptor by Akt require Mdm2 E3 ligase. EMBO Journal 21 4037-4048. (doi:10.1093/ $\mathrm{emboj} / \mathrm{cdf} 406)$

Lin HK, Hu YC, Yang L, Altuwaijri S, Chen YT, Kang HY \& Chang C 2003 Suppression versus induction of androgen receptor functions by the phosphatidylinositol 3-kinase/Akt pathway in prostate cancer LNCaP cells with different passage numbers. Journal of Biological Chemistry 278 50902-50907. (doi:10.1074/jbc.M300676200)

List HJ, Smith CL, Rodriguez O, Danielsen M \& Riegel AT 1999 Inhibition of histone deacetylation augments dihydrotestosterone induction of androgen receptor levels: an explanation for trichostatin A effects on androgen-induced chromatin remodeling and transcription of the mouse mammary tumor virus promoter. Experimental Cell Research 252 471-478. (doi:10.1006/excr.1999.4638)

Liu S, Yuan Y, Okumura Y, Shinkai N \& Yamauchi H 2010a Camptothecin disrupts androgen receptor signaling and suppresses prostate cancer cell growth. Biochemical and Biophysical Research Communications 394 297-302. (doi:10.1016/j.bbrc.2010.02.164)

Liu Y, Karaca M, Zhang Z, Gioeli D, Earp HS \& Whang YE $2010 b$ Dasatinib inhibits site-specific tyrosine phosphorylation of androgen receptor by Ack1 and Src kinases. Oncogene 29 3208-3216. (doi:10.1038/ onc.2010.103)

Mahajan NP, Liu Y, Majumder S, Warren MR, Parker CE, Mohler JL, Earp HS \& Whang YE 2007 Activated Cdc42-associated kinase Ack1 promotes prostate cancer progression via androgen receptor tyrosine phosphorylation. PNAS 104 8438-8443. (doi:10.1073/pnas.0700420104)

Mahajan K, Challa S, Coppola D, Lawrence H, Luo Y, Gevariya H, Zhu W, Chen YA, Lawrence NJ \& Mahajan NP 2010 Effect of Ack1 tyrosine kinase inhibitor on ligand-independent androgen receptor activity. Prostate 70 1274-1285. (doi:10.1002/pros.21163) 
Martinez ED \& Danielsen M 2002 Loss of androgen receptor transcriptional activity at the G(1)/S transition. Journal of Biological Chemistry 277 29719-29729. (doi:10.1074/jbc.M112134200)

McCall P, Gemmell LK, Mukherjee R, Bartlett JM \& Edwards J 2008 Phosphorylation of the androgen receptor is associated with reduced survival in hormone-refractory prostate cancer patients. British Journal of Cancer 98 1094-1101. (doi:10.1038/sj.bjc.6604152)

McCampbell A, Taye AA, Whitty L, Penney E, Steffan JS \& Fischbeck KH 2001 Histone deacetylase inhibitors reduce polyglutamine toxicity. PNAS 98 15179-15184. (doi:10.1073/pnas.261400698)

Montie HL, Pestell RG \& Merry DE 2011 SIRT1 modulates aggregation and toxicity through deacetylation of the androgen receptor in cell models of SBMA. Journal of Neuroscience 31 17425-17436. (doi:10.1523/JNEUROSCI.3958-11.2011)

Mukherjee S, Thomas M, Dadgar N, Lieberman AP \& Iniguez-Lluhi JA 2009 Small ubiquitin-like modifier (SUMO) modification of the androgen receptor attenuates polyglutamine-mediated aggregation. Journal of Biological Chemistry 284 21296-21306. (doi:10.1074/jbc.M109.011494)

Nan B, Snabboon T, Unni E, Yuan XJ, Whang YE \& Marcelli M 2003 The PTEN tumor suppressor is a negative modulator of androgen receptor transcriptional activity. Journal of Molecular Endocrinology 31 169-183. (doi:10.1677/jme.0.0310169)

Narayanan R, Yepuru M, Szafran AT, Szwarc M, Bohl CE, Young NL, Miller DD, Mancini MA \& Dalton JT 2010 Discovery and mechanistic characterization of a novel selective nuclear androgen receptor exporter for the treatment of prostate cancer. Cancer Research 70 842-851. (doi:10.1158/0008-5472.CAN-09-3206)

Nazareth LV \& Weigel NL 1996 Activation of the human androgen receptor through a protein kinase A signaling pathway. Journal of Biological Chemistry 271 19900-19907. (doi:10.1074/jbc.271.33.19900)

Nishida T \& Yasuda H 2002 PIAS1 and PIASxalpha function as SUMO-E3 ligases toward androgen receptor and repress androgen receptor-dependent transcription. Journal of Biological Chemistry 277 41311-41317. (doi:10.1074/jbc.M206741200)

Palazzolo I, Burnett BG, Young JE, Brenne PL, La Spada AR, Fischbeck KH, Howell BW \& Pennuto M 2007 Akt blocks ligand binding and protects against expanded polyglutamine androgen receptor toxicity. Human Molecular Genetics 16 1593-1603. (doi:10.1093/hmg/ddm109)

Palazzolo I, Stack C, Kong L, Musaro A, Adachi H, Katsuno M, Sobue G, Taylor JP, Sumner CJ, Fischbeck KH et al. 2009 Overexpression of IGF-1 in muscle attenuates disease in a mouse model of spinal and bulbar muscular atrophy. Neuron 63 316-328. (doi:10.1016/j.neuron.2009.07.019)

Ponguta LA, Gregory CW, French FS \& Wilson EM 2008 Site-specific androgen receptor serine phosphorylation linked to epidermal growth factor-dependent growth of castration-recurrent prostate cancer. Journal of Biological Chemistry 283 20989-21001. (doi:10.1074/jbc. M802392200)

Poukka H, Karvonen U, Janne OA \& Palvimo JJ 2000 Covalent modification of the androgen receptor by small ubiquitin-like modifier 1 (SUMO-1). PNAS 97 14145-14150. (doi:10.1073/pnas.97.26.14145)

Rees I, Lee S, Kim H \& Tsai FT 2006 The E3 ubiquitin ligase CHIP binds the androgen receptor in a phosphorylation-dependent manner. Biochimica et Biophysica Acta 1764 1073-1079. (doi:10.1016/j.bbapap.2006.03.013)

Rigas AC, Ozanne DM, Neal DE \& Robson CN 2003 The scaffolding protein RACK1 interacts with androgen receptor and promotes cross-talk through a protein kinase C signaling pathway. Journal of Biological Chemistry 278 46087-46093. (doi:10.1074/jbc.M306219200)

de Ruiter PE, Teuwen R, Trapman J, Dijkema R \& Brinkmann AO 1995 Synergism between androgens and protein kinase-C on androgen-regulated gene expression. Molecular and Cellular Endocrinology 110 R1-R6. (doi:10.1016/0303-7207(95)03534-E)

Salas TR, Kim J, Vakar-Lopez F, Sabichi AL, Troncoso P, Jenster G, Kikuchi A, Chen SY, Shemshedini L, Suraokar M et al. 2004 Glycogen synthase kinase-3 $\beta$ is involved in the phosphorylation and suppression of androgen receptor activity. Journal of Biological Chemistry 279 19191-19200. (doi:10.1074/jbc. M309560200)
Shank LC, Kelley JB, Gioeli D, Yang CS, Spencer A, Allison LA \& Paschal BM 2008 Activation of the DNA-dependent protein kinase stimulates nuclear export of the androgen receptor in vitro. Journal of Biological Chemistry 283 10568-10580. (doi:10.1074/jbc.M800810200)

Sharma M \& Sun Z $20015^{\prime}$ TG3' interacting factor interacts with Sin3A and represses AR-mediated transcription. Molecular Endocrinology 15 1918-1928. (doi:10.1210/me.15.11.1918)

Sharma M, Li X, Wang Y, Zarnegar M, Huang CY, Palvimo JJ, Lim B \& Sun Z 2003 hZimp10 is an androgen receptor co-activator and forms a complex with SUMO-1 at replication foci. EMBO Journal 22 6101-6114. (doi:10.1093/emboj/cdg585)

Shi XB, Ma AH, Xia L, Kung HJ \& de Vere White RW 2002 Functional analysis of 44 mutant androgen receptors from human prostate cancer. Cancer Research 62 1496-1502.

Shigemura K, Isotani S, Wang R, Fujisawa M, Gotoh A, Marshall FF, Zhau HE \& Chung LW 2009 Soluble factors derived from stroma activated androgen receptor phosphorylation in human prostate LNCaP cells: roles of ERK/MAP kinase. Prostate 69 949-955. (doi:10.1002/pros.20944)

Shih HM, Chang CC, Kuo HY \& Lin DY 2007 Daxx mediates SUMOdependent transcriptional control and subnuclear compartmentalization. Biochemical Society Transactions 35 1397-1400. (doi:10.1042/BST0351397)

Shiota M, Yokomizo A, Masubuchi D, Tada Y, Inokuchi J, Eto M, Uchiumi T, Fujimoto N \& Naito S 2010 Tip60 promotes prostate cancer cell proliferation by translocation of androgen receptor into the nucleus. Prostate 70 540-554. (doi:10.1002/pros.21088)

Shu SK, Liu Q, Coppola D \& Cheng JQ 2010 Phosphorylation and activation of androgen receptor by Aurora-A. Journal of Biological Chemistry 285 33045-33053. (doi:10.1074/jbc.M110.121129)

Song CZ, Keller K, Chen Y \& Stamatoyannopoulos G 2003 Functional interplay between CBP and PCAF in acetylation and regulation of transcription factor KLF13 activity. Journal of Molecular Biology 329 207-215. (doi:10.1016/S0022-2836(03)00429-7)

Sugita S, Kawashima H, Tanaka T, Kurisu T, Sugimura K \& Nakatani T 2004 Effect of type I growth factor receptor tyrosine kinase inhibitors on phosphorylation and transactivation activity of the androgen receptor in prostate cancer cells: ligand-independent activation of the N-terminal domain of the androgen receptor. Oncology Reports 11 1273-1279.

Taneja SS, Ha S, Swenson NK, Huang HY, Lee P, Melamed J, Shapiro E, Garabedian MJ \& Logan SK 2005 Cell-specific regulation of androgen receptor phosphorylation in vivo. Journal of Biological Chemistry 280 40916-40924. (doi:10.1074/jbc.M508442200)

Thomas M, Dadgar N, Aphale A, Harrell JM, Kunkel R, Pratt WB \& Lieberman AP 2004 Androgen receptor acetylation site mutations cause trafficking defects, misfolding, and aggregation similar to expanded glutamine tracts. Journal of Biological Chemistry 279 8389-8395. (doi:10.1074/jbc.M311761200)

Ueda T, Mawji NR, Bruchovsky N \& Sadar MD 2002 Ligand-independent activation of the androgen receptor by interleukin- 6 and the role of steroid receptor coactivator-1 in prostate cancer cells. Journal of Biological Chemistry 277 38087-38094. (doi:10.1074/jbc.M203313200)

Wang Q \& Fondell JD 2001 Generation of a mammalian cell line stably expressing a tetracycline-regulated epitope-tagged human androgen receptor: implications for steroid hormone receptor research. Analytical Biochemistry 289 217-230. (doi:10.1006/abio.2000.4960)

Wang LG, Liu XM, Budman DR \& Kreis W 1999a Synergistic effect of estramustine and [3'-keto-Bmtl]-[Val2]-cyclosporine (PSC 833) on the inhibition of androgen receptor phosphorylation in LNCaP cells. Biochemical Pharmacology 58 1115-1121. (doi:10.1016/S00062952(99)00210-5)

Wang LG, Liu XM, Kreis W \& Budman DR 19996 Phosphorylation/ dephosphorylation of androgen receptor as a determinant of androgen agonistic or antagonistic activity. Biochemical and Biophysical Research Communications 259 21-28. (doi:10.1006/bbrc.1999.0655)

Wang L, Lin HK, Hu YC, Xie S, Yang L \& Chang C 2004 Suppression of androgen receptor-mediated transactivation and cell growth by the glycogen synthase kinase $3 \beta$ in prostate cells. Journal of Biological Chemistry 279 32444-32452. (doi:10.1074/jbc.M313963200) 
Wang Z, Guo J, Li Y, Bavarva JH, Qian C, Brahimi-Horn MC, Tan D \& Liu W 2012 Inactivation of androgen-induced regulator ARD1 inhibits androgen receptor acetylation and prostate tumorigenesis. PNAS 109 3053-3058. (doi:10.1073/pnas.1113356109)

Ward RD \& Weigel NL 2009 Steroid receptor phosphorylation: assigning function to site-specific phosphorylation. Biofactors 35 528-536. (doi:10.1002/biof.66)

Wen Y, Hu MC, Makino K, Spohn B, Bartholomeusz G, Yan DH \& Hung MC $2000 \mathrm{HER}-2 /$ neu promotes androgen-independent survival and growth of prostate cancer cells through the Akt pathway. Cancer Research 60 6841-6845.

Wilkinson KA \& Henley JM 2010 Mechanisms, regulation and consequences of protein SUMOylation. Biochemical Journal 428 133-145. (doi:10.1042/ BJ20100158)

Wong HY, Burghoorn JA, Van Leeuwen M, De Ruiter PE, Schippers E, Blok LJ, Li KW, Dekker HL, De Jong L, Trapman J et al. 2004 Phosphorylation of androgen receptor isoforms. Biochemical Journal $\mathbf{3 8 3}$ 267-276. (doi:10.1042/BJ20040683)

Xin L, Teitell MA, Lawson DA, Kwon A, Mellinghoff IK \& Witte ON 2006 Progression of prostate cancer by synergy of AKT with genotropic and nongenotropic actions of the androgen receptor. PNAS 103 7789-7794. (doi:10.1073/pnas.0602567103)

Xu K, Shimelis H, Linn DE, Jiang R, Yang X, Sun F, Guo Z, Chen H, Li W, Kong X et al. 2009 Regulation of androgen receptor transcriptional activity and specificity by RNF6-induced ubiquitination. Cancer Cell 15 270-282. (doi:10.1016/j.ccr.2009.02.021)

Yang CS, Vitto MJ, Busby SA, Garcia BA, Kesler CT, Gioeli D, Shabanowitz J, Hunt DF, Rundell K, Brautigan DL et al. 2005 Simian virus 40 small t antigen mediates conformation-dependent transfer of protein phosphatase 2A onto the androgen receptor. Molecular and Cellular Biology 25 1298-1308. (doi:10.1128/MCB.25.4.1298-1308.2005)

Yang CS, Xin HW, Kelley JB, Spencer A, Brautigan DL \& Paschal BM 2007 Ligand binding to the androgen receptor induces conformational changes that regulate phosphatase interactions. Molecular and Cellular Biology 27 3390-3404. (doi:10.1128/MCB.02411-06)

Yang X, Guo Z, Sun F, Li W, Alfano A, Shimelis H, Chen M, Brodie AM, Chen H, Xiao Z et al. 2011 a Novel membrane-associated androgen receptor splice variant potentiates proliferative and survival responses in prostate cancer cells. Journal of Biological Chemistry 286 36152-36160. (doi:10.1074/jbc.M111.265124)
Yang Y, Tse AK, Li P, Ma Q, Xiang S, Nicosia SV, Seto E, Zhang X \& Bai W $2011 b$ Inhibition of androgen receptor activity by histone deacetylase 4 through receptor SUMOylation. Oncogene 30 2207-2218. (doi:10.1038/ onc.2010.600)

Zhao Y, Lang G, Ito S, Bonnet J, Metzger E, Sawatsubashi S, Suzuki E, Le Guezennec X, Stunnenberg HG, Krasnov A et al. 2008 A TFTC/ STAGA module mediates histone $\mathrm{H} 2 \mathrm{~A}$ and $\mathrm{H} 2 \mathrm{~B}$ deubiquitination, coactivates nuclear receptors, and counteracts heterochromatin silencing. Molecular Cell 29 92-101. (doi:10.1016/j.molcel.2007.12.011)

Zheng Z, Cai C, Omwancha J, Chen SY, Baslan T \& Shemshedini L 2006 SUMO-3 enhances androgen receptor transcriptional activity through a sumoylation-independent mechanism in prostate cancer cells. Journal of Biological Chemistry 281 4002-4012. (doi:10.1074/jbc. M509260200)

Zhou ZX, Wong CI, Sar M \& Wilson EM 1994 The androgen receptor: an overview. Recent Progress in Hormone Research $49249-274$.

Zhou ZX, Kemppainen JA \& Wilson EM 1995 Identification of three proline-directed phosphorylation sites in the human androgen receptor. Molecular Endocrinology 9 605-615. (doi:10.1210/me.9.5.605)

Zhu Z, Becklin RR, Desiderio DM \& Dalton JT 2001 Identification of a novel phosphorylation site in human androgen receptor by mass spectrometry. Biochemical and Biophysical Research Communications 284 836-844. (doi:10.1006/bbrc.2001.5030)

Zong H, Chi Y, Wang Y, Yang Y, Zhang L, Chen H, Jiang J, Li Z, Hong Y, Wang $\mathrm{H}$ et al. 2007 Cyclin D3/CDK11p58 complex is involved in the repression of androgen receptor. Molecular and Cellular Biology 27 7125-7142. (doi:10.1128/MCB.01753-06)

Zoubeidi A, Zardan A, Beraldi E, Fazli L, Sowery R, Rennie P, Nelson C \& Gleave M 2007 Cooperative interactions between androgen receptor (AR) and heat-shock protein 27 facilitate AR transcriptional activity. Cancer Research 67 10455-10465. (doi:10.1158/0008-5472.CAN-07-2057)

Received in final form 31 July 2012

Accepted 3 August 2012

Made available online as an Accepted Preprint 7 August 2012 